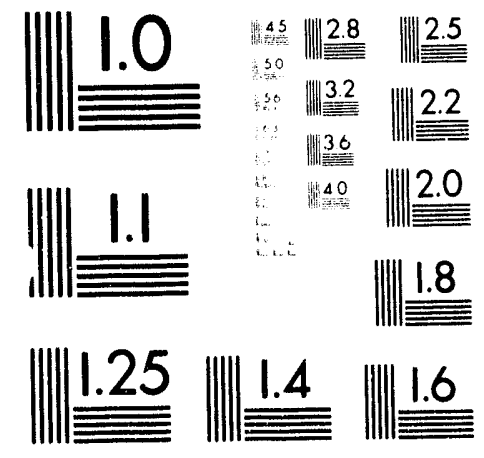



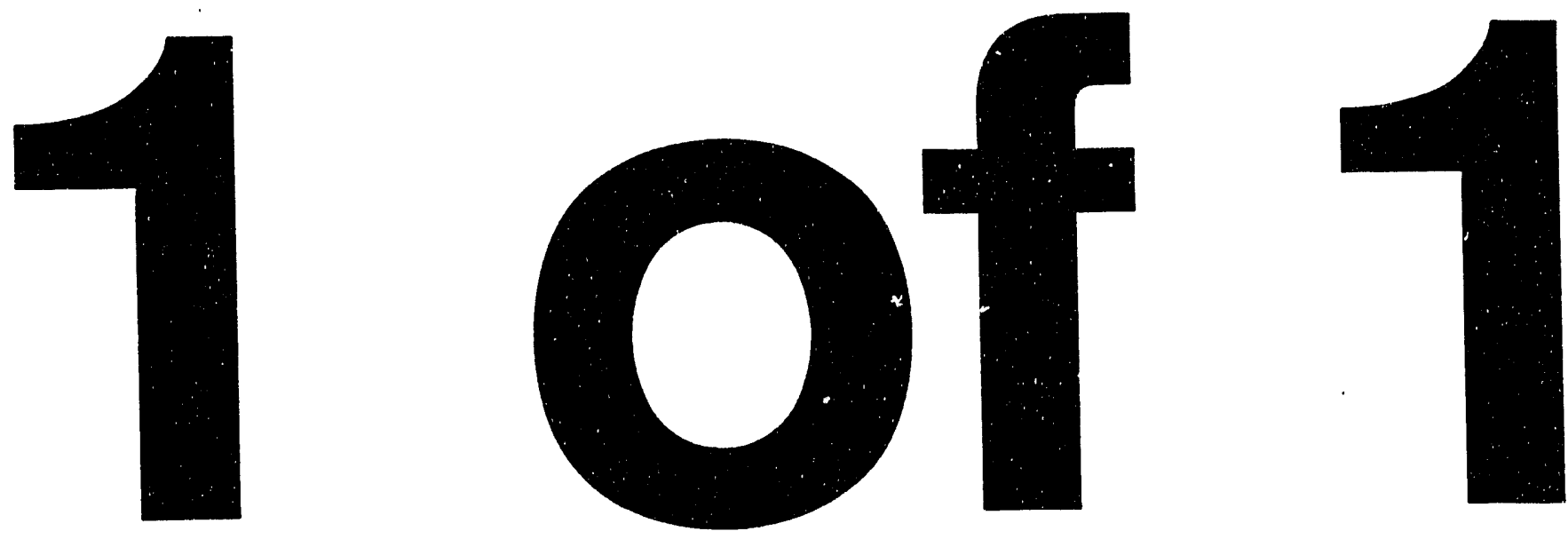
Distribution

Category UC-700

SAND93-0218

Unlimited Release

Printed July 1993

\title{
Mission Hazard Assessment for STARS Mission 1 (M1) in the Marshall Islands Area
}

\author{
David E. Outka \\ Robert A. LaFarge \\ Flight Dynamics Department \\ Sandia National Laboratories \\ Albuquerque, New Mexico 87185
}

\begin{abstract}
A mission hazard assessment has been performed for the Strategic Target System Mission 1 (known as STARS M1) for hazards due to potential debris impact in the Marshall Islands area. The work was performed at Sandia National Laboratories as a result of discussions with Kwajalein Missile Range (KMR) safety officers. The STARS M1 rocket will be launched from the Kauai Test Facility (KTF), Hawaii, and deliver two payloads to within the viewing range of sensors located on the Kwajalein Atoll. The purpose of this work has been to estimate upper bounds for expected casualty rates and impact probability for the Marshall Islands areas which adjoin the STARS M1 instantaneous impact point (IIP) trace. This report documents the methodology and results of the analysis.
\end{abstract}

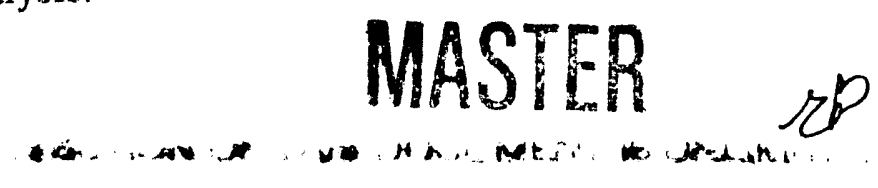


The work described in this report was conducted under case number 1751.500 during the months of April through December, 1991. Originally distributed as a memo to the ranges in the Spring of 1992, the current SAND report version differs primarily in tormat. 


\section{Table of Contents}

Executive Summary . . . . . . . . . . . . . . . . . . . iii

Summary of Results . . . . . . . . . . . . . . . . . . . . iii

The STARS M1 Hazard Assessment . . . . . . . . . . . . . . . . . . . 1

The STARS Vehicle . . . . . . . . . . . . . . . . . . . .

Overview of the Analysis Process . . . . . . . . . . . . . . . . .

Required Assumptions . . . . . . . . . . . . . . . . . . . . . . . .

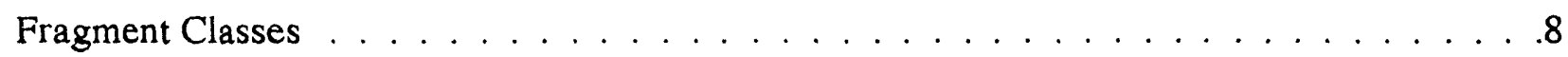

Third Stage Impact Mode Categories . . . . . . . . . . . . . . . . . . . . 12

Failure Probabilities . . . . . . . . . . . . . . . . . . . . 13

Tumble Turn Simulations . . . . . . . . . . . . . . . . . . . . . . 17

Statistical Modeling of the Failure Modes. . . . . . . . . . . . . . . . . 18

Fragment Impact Distribution . . . . . . . . . . . . . . . . . . . . . . . . . . 19

Computation of the Impact Density Map . . . . . . . . . . . . . . . . . 20

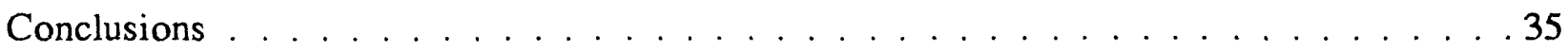

Appendix A. Raw Impact Data Plots . . . . . . . . . . . . . . . . 36 


\section{List of Figures}

Figure 1: STARS M1 Approaches Kwajalein Through the Corridor to the North . . . . . . 2

Figure $2:$ The STARS Vehicle . . . . . . . . . . . . . . . . 3

Figure 3: The STARS Third Stage in Launch Configuration . . . . . . . . . . . . . . . 4

Figure 4: The Orbus 1 STARS Third Stage Motor . . . . . . . . . . . . . . . . . 5

Figure 5: Orbus Motor Aft Dome and Shaped Charge Configuration. . . . . . . . . . . . . 9

Figure 6: Aerothermal Demise of the STARS Third Stage . . . . . . . . . . . . . . . . 10

Figure 7: Impact Density Map: 3 Second Delay Between Failure and FTS Activation . . . . . . . . . . . . . . . . . . . . . . . 23

Figure 8: Impact Density Map: 4 Second Delay Between Failure and FTS Activation . . . . . . . . . . . . . . . . . . . . . . . . . . . 24

Figure 9: Impact Density Map: 3 Second Delay Between Failure and FTS Activation, Spontaneous Destruct Probability $=1.0 \ldots \ldots \ldots . \ldots . \ldots . \ldots 25$

Figure 10: Impact Density Map: 4 Second Delay Between Failure and FTS Activation, Spontaneous Destruct Probability $=1.0$. 26

Figure 11: Hard Over Nozzle Tumble Turn Failure Mode With Initial State Covariance Matrix and With 3 Second Delay . . . . . . . . . . . . . . . . . . . . . 36

Figure 12: Hard Over Nozzle Tumble Turn Failure Mode With Initial State Covariance Matrix and With 4 Second Delay . . . . . . . . . . . . . . . . . . . . . 37

Figure 13: Stuck Nozzle Tumble Turn Failure Mode With Initial State Covariance Matrix and With 3 Second Delay . . . . . . . . . . . . . . . . . . . . . 38

Figure 14: Stuck Nozzle Tumble Turn Failure Mode With Initial State Covariance Matrix and With 4 Second Delay

Figure 15: Null Position Nozzle Tumble Turn Failure Mode With Initial State Covariance Matrix and With 3 Second Delay

Figure 16: Null Position Nozzle Tumble Turn Failure Mode With Initial State Covariance Matrix and With 4 Second Delay

Figure 17: Instantaneous Destruct Failure Mode With Initial State Covariance Matrix 
Figure 18: Hard Over Nozzle Tumble Turn Failure Mode With 3 Second Delay Between Failure on Nominal Trajectory and FTS Activation

Figure 19: Hard Over Nozzle Tumble Turn Failure Mode With 4 Second Delay Between Failure on Nominal Trajectory and FTS Activation

Figure 20: Stuck Nozzle Tumble Turn Failure Mode With 3 Second Delay Between Failure on Nominal Trajectory and FTS Activation

Figure 21: Stuck Nozzle Tumble Turn Failure Mode With 4 Second Delay Between Failure on Nominal Trajectory and FTS Activation

Figure 22: Null Position Nozzle Tumble Turn Failure Mode With 3 Second Delay Between Failure on Nominal Trajectory and FTS Activation

Figure 23: Null Position Nozzle Tumble Turn Failure Mode With 4 Second Delay Between Failure on Nominal Trajectory and FTS Activation

Figure 24: Instantaneous Destruct Failure Mode on Nominal Trajectory. 


\section{List of Tables}

Table 1: Fragment Velocities due to FTS Activation During Third Stage Burn . . . . . . . .8

Table 2: Fragment Classes Which Impact the Earth's Surface . . . . . . . . . . . . . . . 11

Table 3: Reliability of Components Which Could Cause a Tumble Turn . . . . . . . . . . 13

Table 4: Component Reliability Potentially Related to a Null-Positioned Nozzle Failure . . 14

Table 5: Component Reliability Potentially Related to a Hard-over Nozzle Failure . . . . . 15

Table 6: Component Reliability Potentially Related to a Stuck Nozzle Failure . . . . . . . 15

Table 7: Reliability of Components For Which Failure Results in Sudden Vehicle Destruction. . . . . . . . . . . . . . . . . . . 16

Table 8: Probability of Events Which Lead to Impacts in the Downrange Area. . . . . . . 17

Table 9: The Defining Parameters for the Impact Probability Density Functions . . . . . . 21

Table 10: The Bivariate Craussian Density Function for the Enpact Probability Density Functions . . . . . . . . . . . . . . . . . 21

Table 11: The Impact Density Function for an Arbitrary Longitude and Latitude . . . . . . 22

Table 12: Land Impact Probabilities and Expected Casualties: 3 Second FTS Delay . . . . . 27

Table 13: Land Impact Probabilities and Expected Casualties: 4 Second FTS Delay . . . . . 30

Table 14: Probabilities of Impacts Within Keepout Zones. . . . . . . . . . . . . . . . . . 33 


\section{The STARS M1 Hazard Assessment}

The STARS Mission 1 (known as STARS M1) is planned to carry two Strategic Defense payloads from the Kauai Test Facility (KTF) to the Marshall Islands area. The terminal portions of the payload trajectories will be observed from various sensor platforms on Kwajalein Atoll and the surrounding area. Primary flight safety responsibility for the mission is assigned to the Naval Air Warfare Center (NAWC), Weapons Division, with cooperation of the Pacific Missile Range Facility (PMRF) and the Kwajalein Missile Range (KMR). Sandia National Laboratories is tasked to provide supporting data and analysis, as requested by the ranges.

As part of this support, a STARS M1 mission hazard assessment has been performed for hazards due to potential debris impact in the Marshall Islands area. The need for this work was recognized following discussions with Kwajalein Missile Range (KMR) safety officers. The objective of the hazard assessment was to estimate upper bounds for expected casualty rates and impact probability for the Marshall Islands areas which adjoin the STARS M1 instantaneous impact point (IIP) trace. This report documents the methodology and results of the hazard analysis.

To keep the IIP well away from inhabited areas, a dogleg maneuver is periormed late in the burn of the third stage. This maneuver causes the IIP to approach Kwajalein Atoll from the north, through the widest available corridor (Figure 1). Even so, the software KMR intended to use to perform a real-time safety assessment indicated that the mission could not be performed as planned. However, the real-time software did not provide any information on the probability of a hazardous event actually occurring. Nor was the fact that there were very few people and very little land area in comparison to the large amount of ocean area considered. Simple calculations could be performed which showed that the number of debris impacts per unit area were likely to be extremely low over the areas of concern. A more rigorous treatment of the subject would lay to rest concerns that the simple calculations did not cover all worst case possibilities.

It was known that TRW provided probabilistic hazard assessments in support of Minuteman launches from Vandenburg Air Force Base to KMR, but neither KMR nor Sandia had experience with tue probabilistic hazard assessments for rocket missions. Since it appeared that support from TRW would be unfeasible, it was proposed to KMR that Sandia perform a mission hazard assessment for the STARS M1 flight. The intent of this work has been to estimate upper bounds for expected casualty rates and impact probability for the Marshall Islands areas which adjoin the STARS M1 IIP ground track. It is anticipated that this information will assist KMR in making a judgement as to the hazards associated with the mission. In addition to hazards to people on the ground, this data should be useful in estimating the hazards to aircraft, to shipping, and to groundbased assets such as radar equipment. 


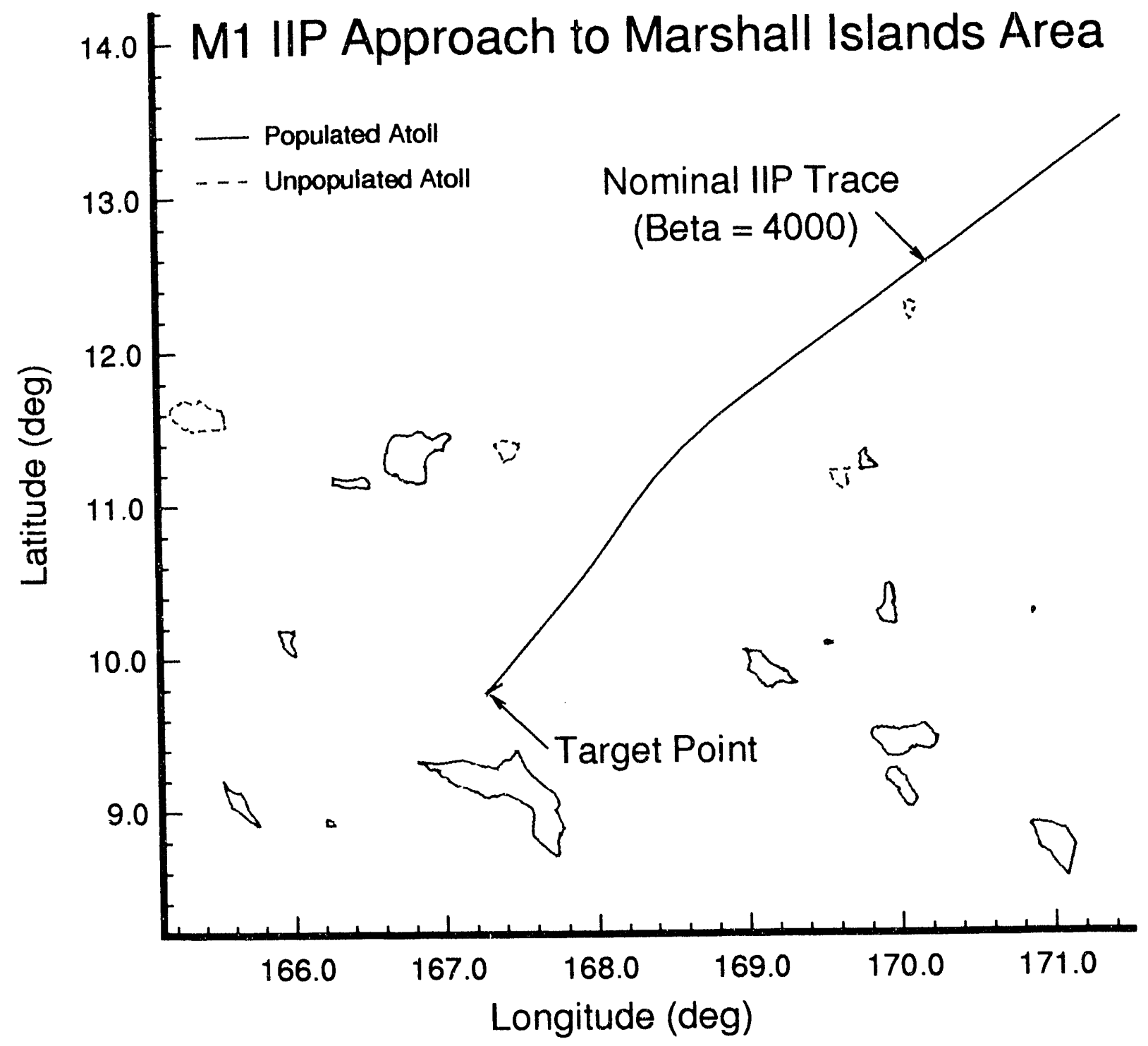

Figure 1: STARS M1 Approaches Kwajalein Through the Corridor to the North 


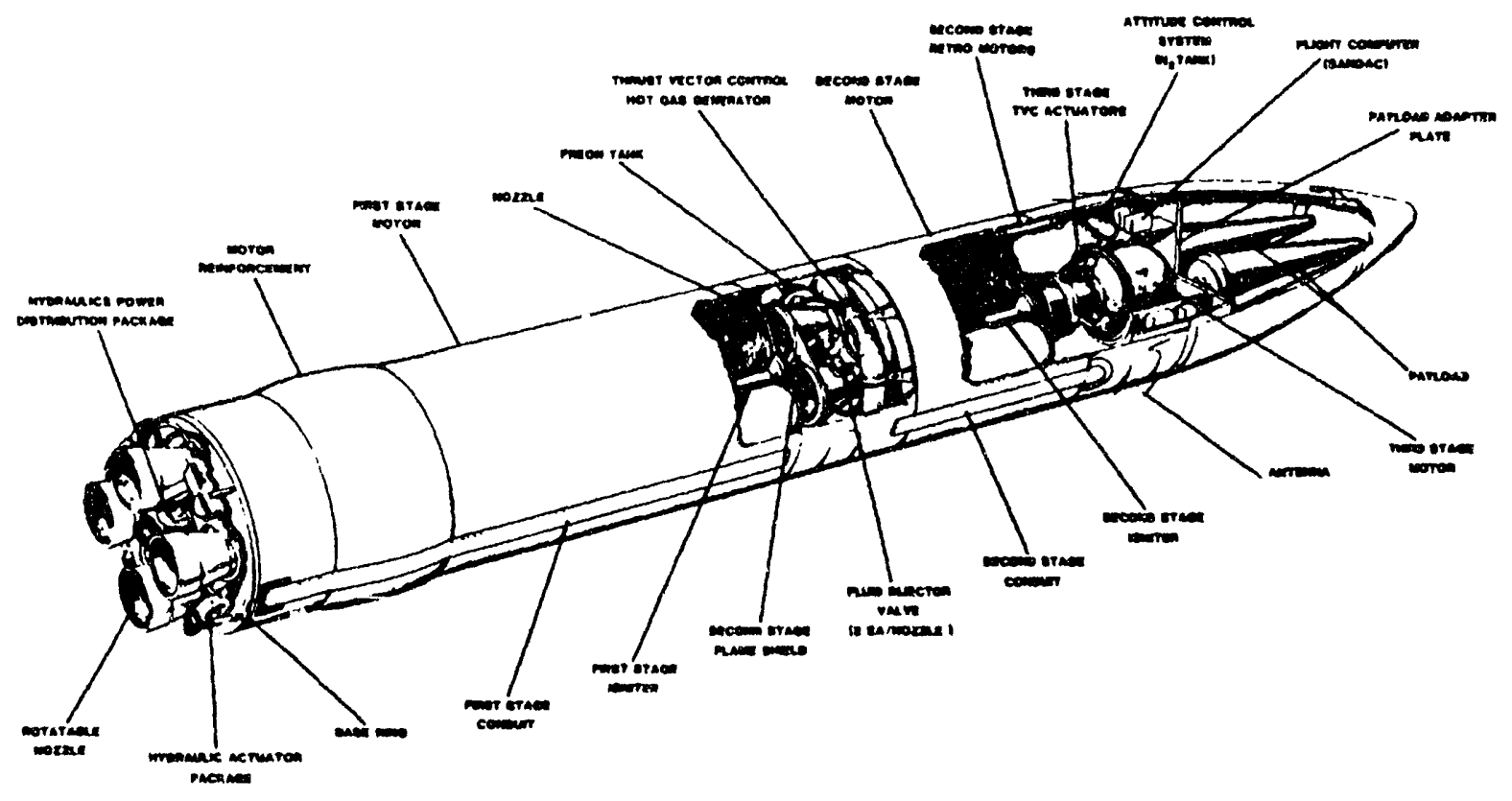

Figure 2: The STARS Vehicle

\section{The STARS Vehicle}

The STARS vehicle consists of three stages (Figure 2). The first two stages are derived from retired Polaris A3 fleet ballistic missile assets. Since only the third stage and its payloads reach the Marshall Islands area, the first two stages are not considered in this report. The third stage (Figure 3) is an all new Sandia design, added to meet the objectives of the program. The STARS Orbus 1 third stage motor, shown in Figure 4, was designed and built to Sandia specifications by the Chemical Sys'icms Division of United Technologies Corporation.

\section{Qverview of the Analysis Process}

The analysis process begins with a failure mode analysis. The components whose failure could cause a flight safety hazard in the form of a trajectory deviation are identified and the failure rate of each of these components is determined. Next, the nature of the trajectory deviation resulting from each specific component failure is identified, permitting the effects of some failure modes to be combined. For example, the third stage nozzle might become fixed in a given position due either to some sort of mechanical failure or to a faulty electrical signal; the effect on the trajectory would be the same in either case. 


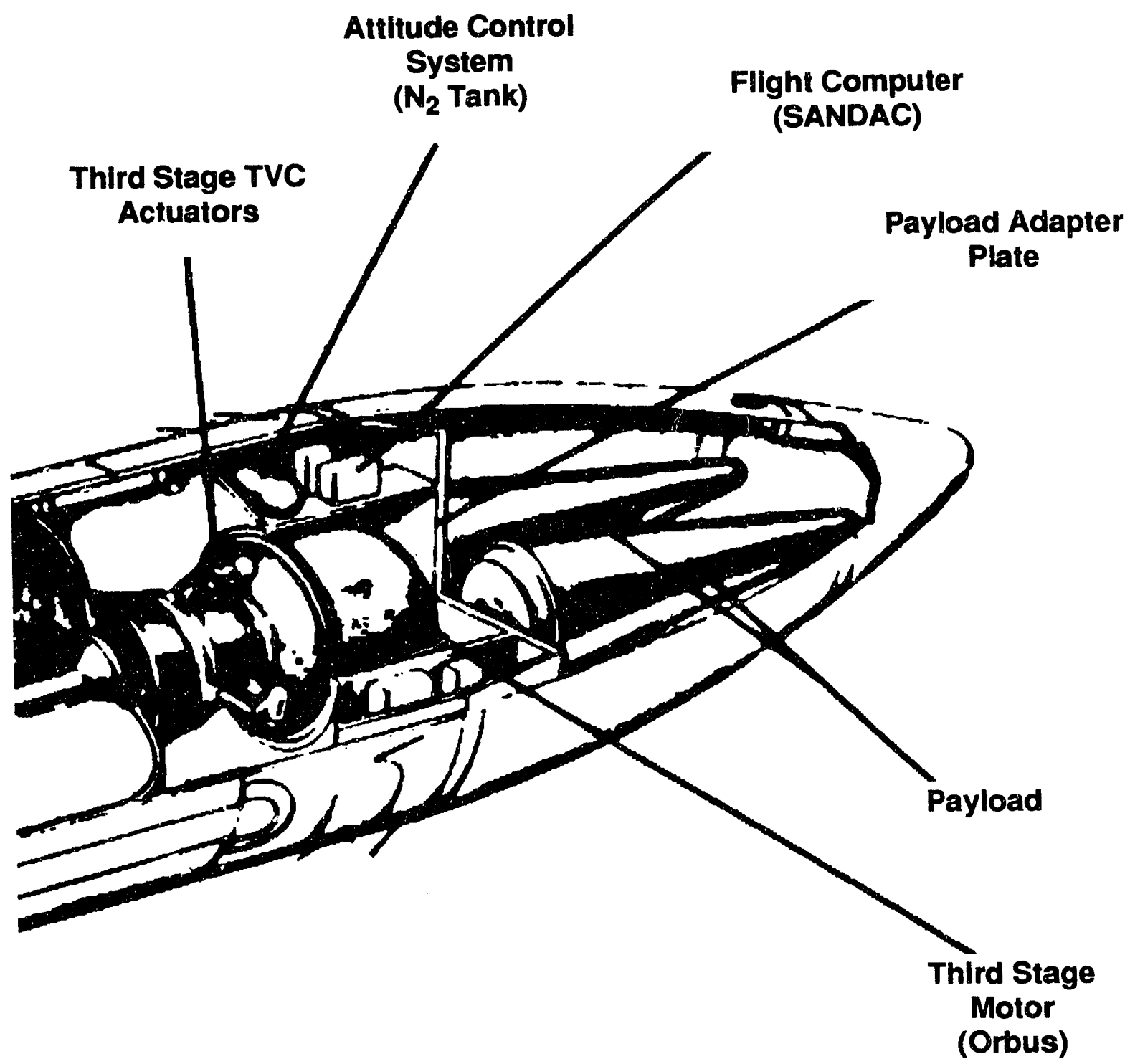

Figure 3: The STARS Third Stage in Launch Configuration 


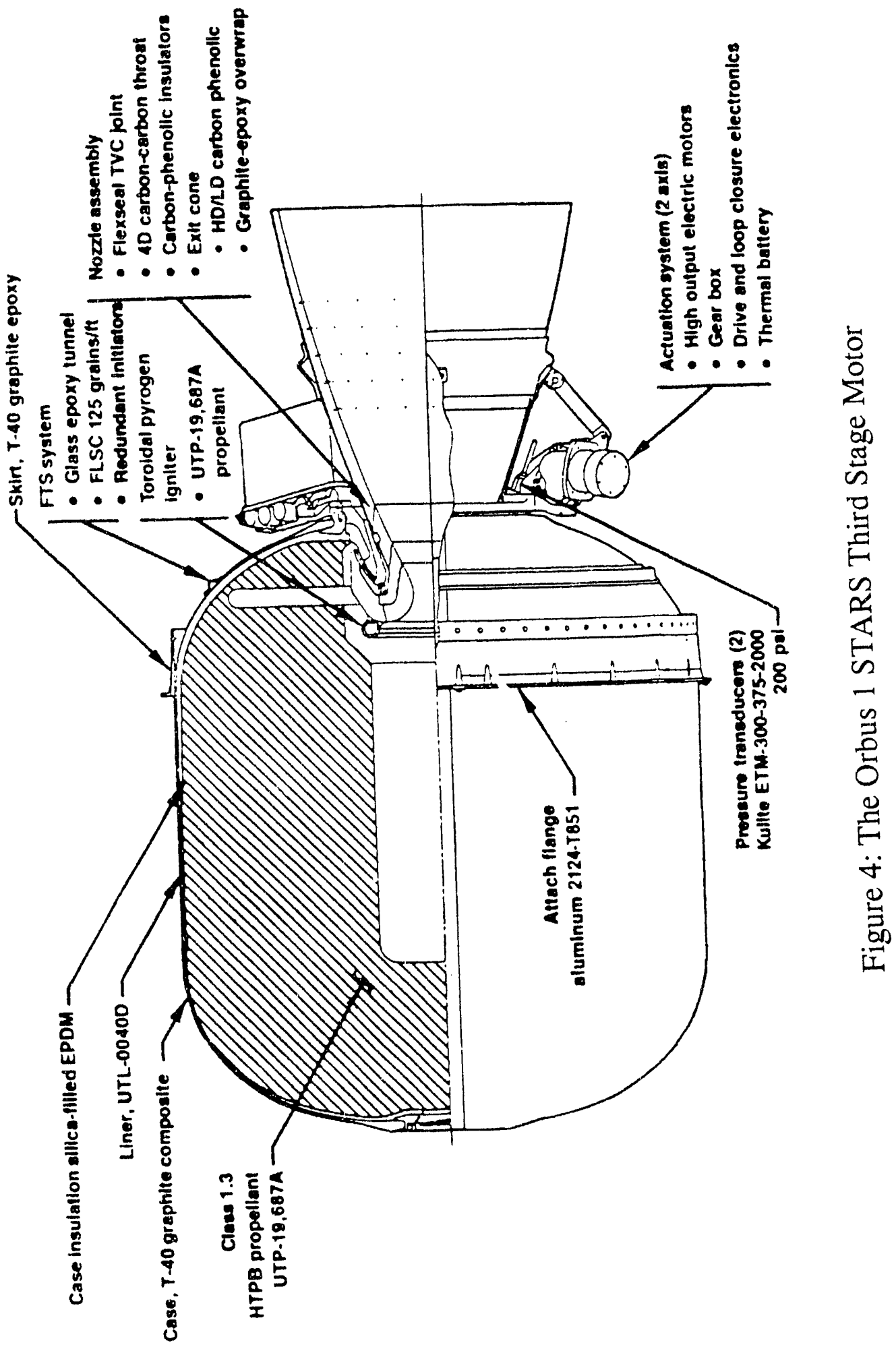


A trajectory simulation is used that repeatedly simulates each failure mode. Specific parameters are varied either systematically or randomly (in a Monte Carlo sense) in order to build up a data base correlating failures to debris impact locations. The parameters varied systematically include:

1. the time of failure, varied from 18 to 38 seconds after third stage ignition in one second increments,

2. the failure mode category (four were defined: see page 12),

3. delay time between failure and FTS activation, ${ }^{1}$

4. the fragment class, of which 19 were defined (see Table 2 on page 11).

Parameters varied randomly about nominal, via a statistical model, include

1. the third stage state vector at the time of a component failure,

2. details of the failure mode (such as angle of nozzle position: see page 17),

3. fragment velocities induced by FTS activation,

4. wind profile.

A total of 240996 different impact points were generated using the various combinations of these parameters for each delay time. ${ }^{2}$ In addition, 19019 trajectory variations of normal mission completion were computed. ${ }^{3}$ For each of the systematically varied parameters, a normal (Gaussian) ground impact probability density function (PDF) was defined as a function of latitude and longitude. Each such PDF represents the likelihood that a given fragment of this class will impact in a given unit area on the earth's surface, assuming that the vehicle failed at the assumed time in the assumed mode with the assumed delay prior to FTS activation. For a given spot on the earth, these PDFs are then integrated numerically over all failure times and multiplied by the probability of that failure mode occurring and by the number of fragments in that fragment class. The result is summed with similar results for the other failure modes and fragment classes to obtain the overall probability of any fragment impacting at that spot (per unit area) for the assumed FTS delay interval.

By computing such probabilities over a grid of locations on the earth's surface, an impact probability contour map can be generated. Alternately, a numerical integration over a region of interest can be performed to determine the probability of an impact in that region. From the results of such a calculation, in conjunction with population data, the expected casualty rate can be derived.

1. Delay times of 3 and 4 seconds were used, as suggested in discussions with LaPoint and Valencia of the KMR range safety office.

2. 151 state vectors at each of 21 failure times for 4 failure modes and 19 fragment classes.

3. $19 \mathrm{fr}$ ?gment classes for 1001 normal mission completion state vectors at third stage burn out. 


\section{Required Assumptions}

Due to the number of possible failure scenarios and the complexity of the STARS system, a number of assumptions have been made in order to complete this analysis in a timely manner. Except as noted, each assumption is conservative in nature; i.e., by making the assumption the resulting hazard estimate is greater than that resulting from the implementation of a more accurate model. In this way the estimates of casualty and impact into undesirable areas are assured to be greater than the actual value. Assumptions that might be considered non-conservative are few, and the rational for making these assumptions is given.

The IIP for the STARS M1 mission is several hundred nautical miles away from the Marshall Islands area until after third stage ignition. Therefore, only those vehicle systems which remain during the third stage burn have been considered for the KMR area flight safety. Descriptions of these components, along with reliability estimates, are available in the STARS Flight Safety Data Package and other documents. 4.5

In addition, the IIP for all off-nominal flights does not come within $100 \mathrm{~nm}$ of the nearest inhabited atoll until 20 seconds after third stage ignition. Hence it is assumed that failures prior to 18 seconds after third stage ignition (to be conservative) are not contributors to the hazards in the Marshall Islands area.

The nominal trajectory for these studies was that which was current at the time the work was initiated in the Spring of 1991 . Since then, the third stage performance model, ${ }^{6}$ the vehicle mass properties, ${ }^{7}$ and the estimates of the initial phases of the trajectory have been revised slightly, resultingr. in a slightly different final nominal trajectory. ${ }^{8}$ However, the difference between the nominal trajectory used for this report and the final M1 trajectory is small (less than one standard deviation), since the target points and dogleg turns have not changed and changes to the vehicle physical model is slight. Hence, the preliminary nominal trajectory used for this analysis can be considered fully adequate for the purposes of this report.

4. Abbott, K. C. and Plowman, R. W. (7222), Strategic " arget System (STARS) Predicted Mission Reliability for Flight Test Unit - I (FTU-J). Sandia National Laboratories memo to R. L. Eno (7520) dated October 1. 1990.

5. Abbott, K. C. and Plowman, R. W. (7222), S7ARS Third Stage Thrust Vector Actuator (TVA) Assembly Failure Probabilitie's, Sandia National Laboratories memo to R. L. Eno (7520) dated September 18, 1990.

6. Outka. David E.. Orbus Flight Motor Performance Data, Sandia National Laboratories memo to Distribution. dated April 2, 1991.

7. Weber, M. R.. STARS MI Missile Unclassified Mass Properties, Sandia National Laboratories memo to Distribution, dated July 30, 1991.

8. Millard, William A., Outka, David E., and White. John E., Trajectory and Flight Safety for the STARS M1 Mission. Sandia National Laboratories report to Distribution. dated April 26. 1993. 


\section{Fragment Classes}

A number of debris fragments are created upon activati in of the FTS during third stage burn, and additional fragments are created due to aerodynamic neating and loading. The exact number of such fragments is impossible to predict. To be conservative, a large number of potentially hazardous fragments has been assumed. Specifically, fragments assumed to reach the earth include 106 from payload Test Object 1 (T. O. 1), 24 from payload T. O. 2, and 16 from the third stage. The debris are grouped into fragment classes, as described later, designed to represent the broad range of fragments which might be expected. Note that it is likely that some fragments assumed to reach the earth will actually fully demise due to aerothermal heating. Moreover, some of the fragments counted as hazardous are likely to impact the earth with insufficient energy to pose a safety threat. ${ }^{9}$ However, this conservative analysis assumes that all fragments survive aerothermal heating and low energy fragments are not ignored.

\begin{tabular}{|c|c|c|c|c|c|c|c|}
\hline \multirow[t]{2}{*}{$\begin{array}{c}\text { Item } \\
\text { Number }\end{array}$} & \multirow[t]{2}{*}{$\begin{array}{l}\text { Fragment } \\
\text { Description }\end{array}$} & \multirow[t]{2}{*}{$\begin{array}{l}\text { Number } \\
\text { of } \\
\text { Pieces }\end{array}$} & \multicolumn{4}{|c|}{$\begin{array}{l}\text { Mean Incremental Velocity } \\
\quad(\mathrm{ft} / \mathrm{sec})\end{array}$} & \multirow[t]{2}{*}{$\begin{array}{l}\text { Standard } \\
\text { Deviation } \\
\text { of Velocity }\end{array}$} \\
\hline & & & $2 \mathrm{sec}$ & $22 \mathrm{sec}$ & $31 \mathrm{sec}$ & $38 \mathrm{sec}$ & \\
\hline 1 & $\begin{array}{l}\text { Thrust Vector } \\
\text { Actuator }\end{array}$ & 2 & 20 & 74 & 78 & 53 & $15 \%$ \\
\hline 2 & $\begin{array}{l}\text { TVC Electronics } \\
\text { Package }\end{array}$ & 1 & 20 & 74 & 78 & 53 & $15 \%$ \\
\hline 3 & $\begin{array}{l}\text { Motor Aft Dome } \\
\text { and Nozzle }\end{array}$ & 1 & 20 & 74 & 78 & 53 & $15 \%$ \\
\hline 4 & Payload & 2 & 8 & 16 & 19 & 17 & $4 \mathrm{ft} / \mathrm{sec}$ \\
\hline 5 & $\begin{array}{l}\text { Third Stage } \\
\text { Booster }\end{array}$ & 1 & 8 & 16 & 19 & 17 & $3 \mathrm{ft} / \mathrm{sec}$ \\
\hline
\end{tabular}

Table 1: Fragment Velocities due to FTS Activation During Third Stage Burn

Considerable attention has been given to the relative velocities imparted to the vehicle fragments upon activation of the FTS while the third stage (Orbus) motor is thrusting. Original estimates were too conservative in that they did not take into account the energy dissipated by the section of case structure not cut by the shaped charge. Subsequently, an analysis has been performed which examines the stress in the aft dome case material following FTS activation. ${ }^{10.11}$ It turns out that the un-

9. Energy relationships between impacting fragments and hazard classes are discussed, for example, in Document 315-79. Risk Analysis Techniques, prepared by the Range Safety Group, Range Commanders Council, March, 1979

10. Gwinn, K. W., STARS Thrust Termination with Variable Pressure Louding, Sandia National Laboratories memo to Bob Mata dated July 25, 1991. 


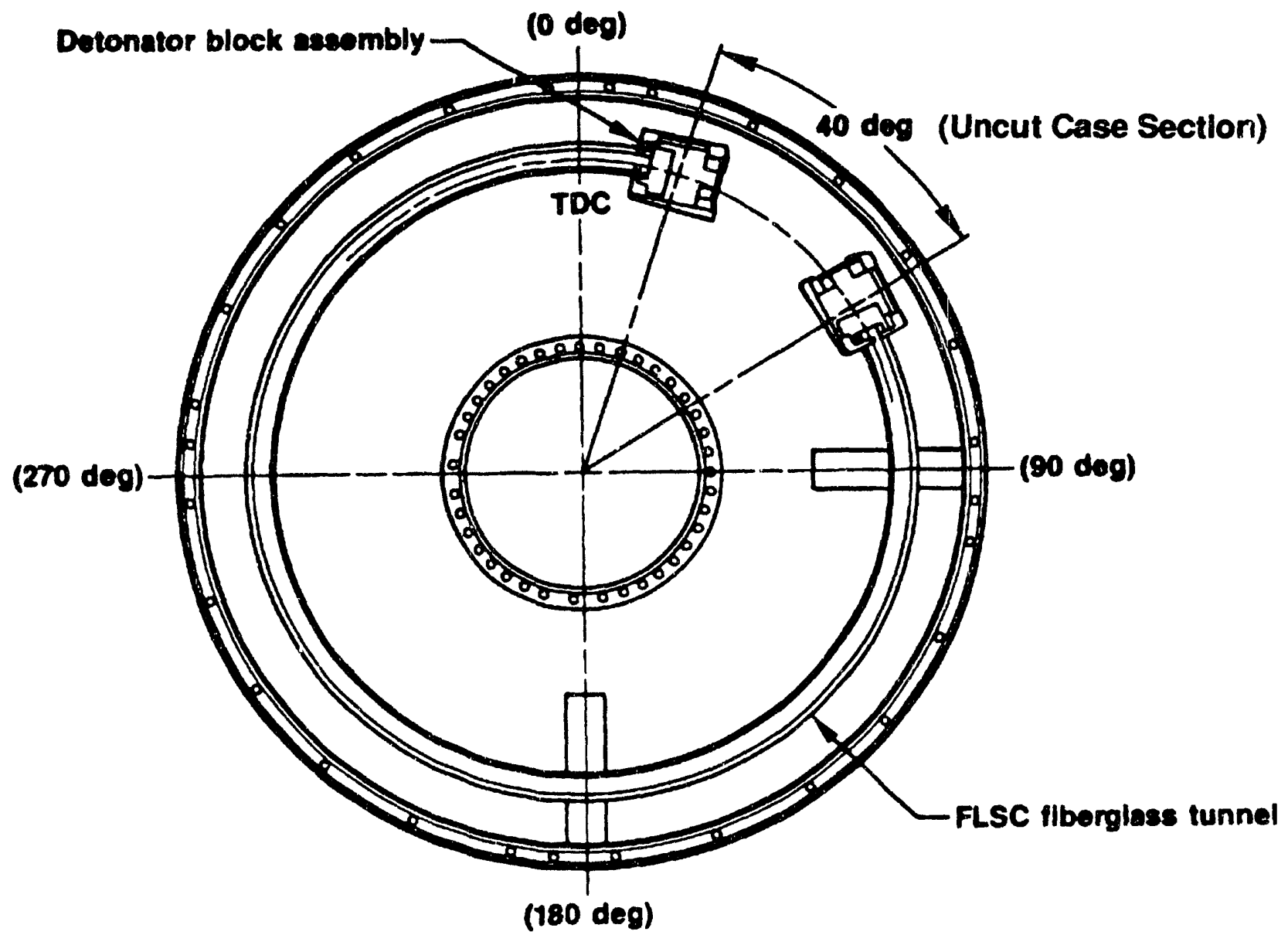

CSD-V- 52907

Figure 5: Orbus Motor Aft Dome and Shaped Charge Configuration

rut case section (see Figure 5) absorbs a significant amount of energy. Moreover, the cut portion $c_{i}$ the aft dome quickly deforms until it is wrapped around the nozzle and attached TVC components, thus increasing the area available for the hot propellant gas to vent while reducing the area over which the gas can accelerate the aft porticns of the mo'or. The results of this analysis are summarized in Table 1.

To reduce the total required number of trajectory calculations, firgment classes were identified for debris resulting from aerothermal breakup of some of the major fragmints. The model for the aerothermal demise of the third stage was developed by Donald L. Potter of Sandia's Thermophysics Department. An overview of the model is sketched in Figure 6. Demise models for the payloads were developed by assuming each undergoes significant breakup and, for T. O. 1, from observation of similar objects tested previously. The 19 fragment classes defined are listed in Table 2.

11. Outka, D. E., STARS Third Stage Fragment Velocities due to Thrust Termination, Sandia National Laboratories memo to W. P. Wolfe dated August 7, 1991. 


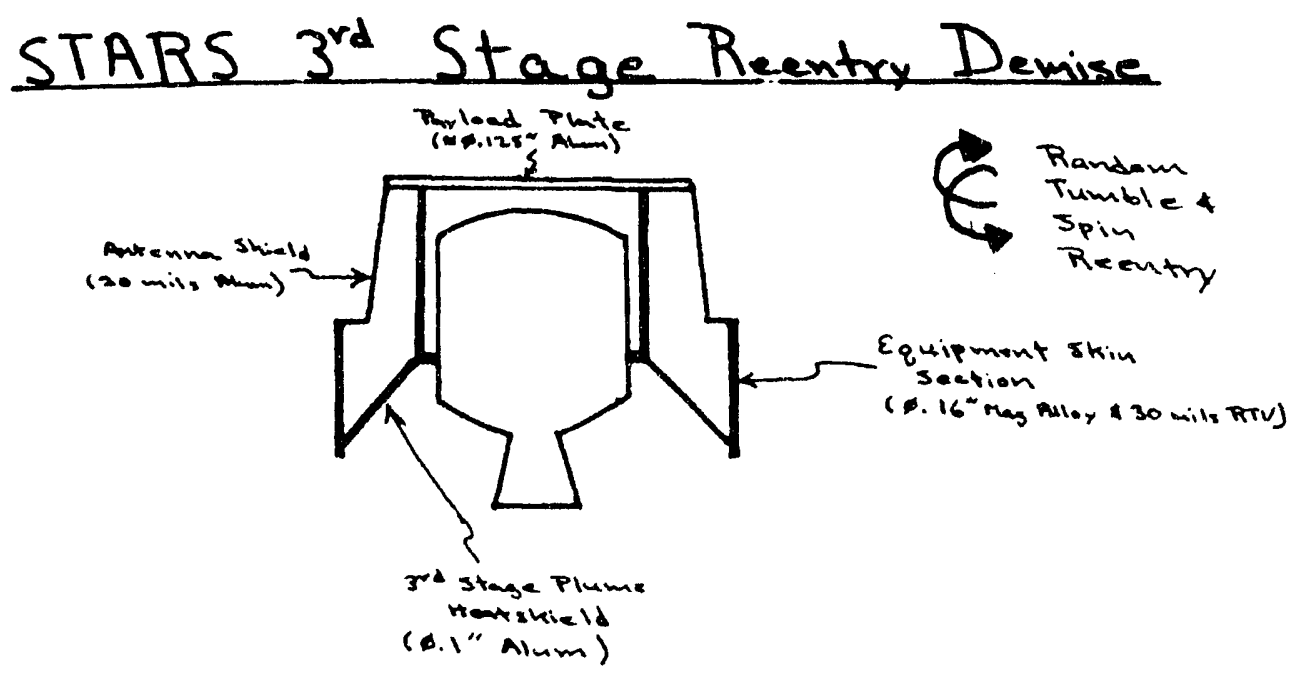

- $\approx 215 \mathrm{KFt}$

- Rutema shivild Failure

- Degin Decirculatiua Heating
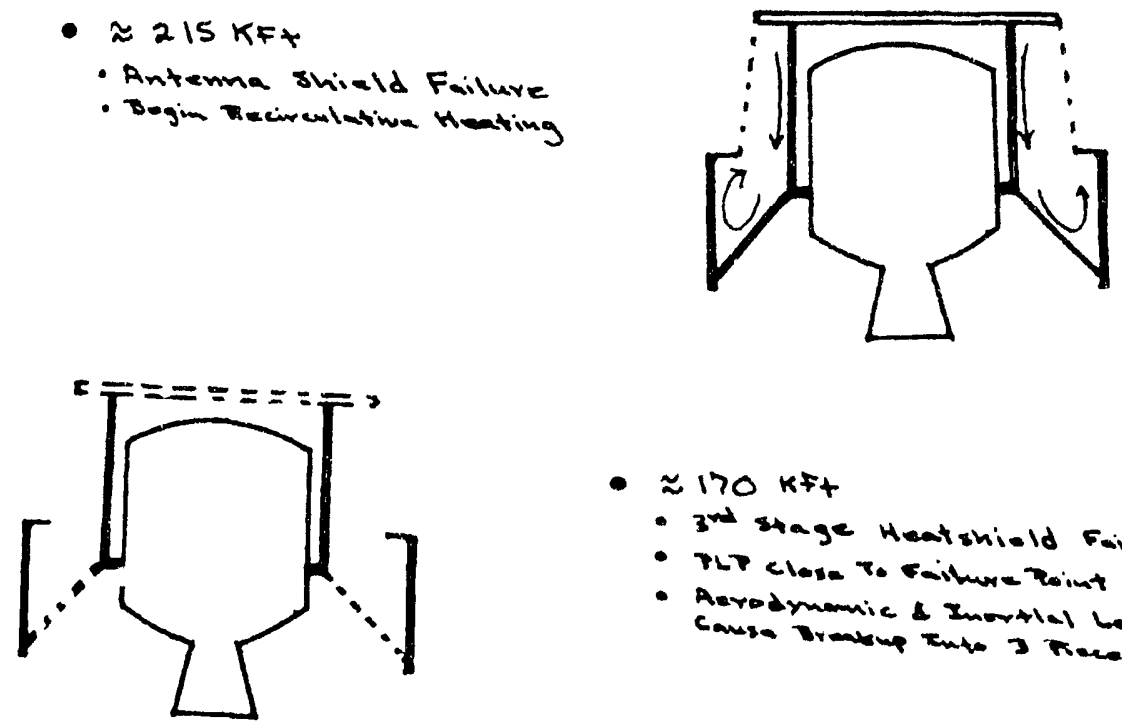

- $\approx 170 \mathrm{kFt}$

- 3nt stage Heatinield Failure

- TLT clase To Faihuretesint

- Aerodrmanic \& Inortial

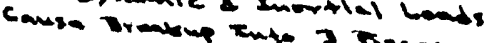
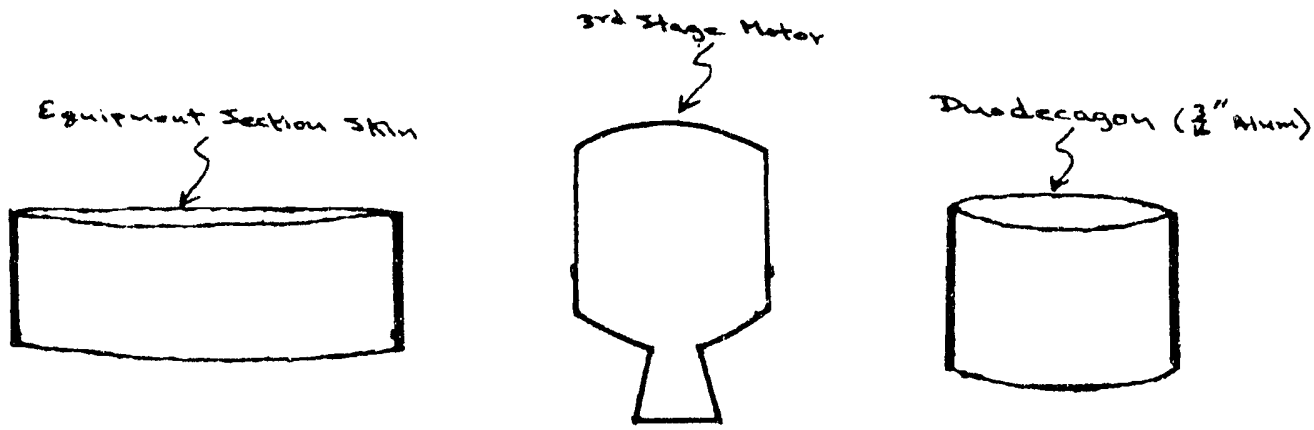

Figure 6: Aerothermal Demise of the STARS Third Stage 
Mission Hazard Assessment for STARS Mission 1 (M1) in the Marshall Islands Area

\begin{tabular}{|c|c|c|c|c|}
\hline $\begin{array}{l}\text { Class } \\
\text { ID }\end{array}$ & Description & $\begin{array}{c}\text { Quantit } \\
\mathbf{y}\end{array}$ & $\begin{array}{c}\text { Approximate } \\
\text { Mass } \\
\left(\mathrm{lb}_{\mathrm{m}}\right)\end{array}$ & $\begin{array}{c}\text { Approximate } \\
\text { Beta } \\
\left(\mathrm{lb} / \mathrm{ft}^{2}\right)\end{array}$ \\
\hline 1 & $\begin{array}{l}\text { nozzle, aft dome of Orbus } \\
\text { motor }\end{array}$ & 1 & 54.2 & 50 \\
\hline 2 & third stage skin (ring) & 1 & 46.9 & $6-13$ \\
\hline 3 & $\begin{array}{l}\text { dodecagon with compo- } \\
\text { nents }\end{array}$ & 10 & $1.0-287$ & $41-78$ \\
\hline 4 & spent Orbus motor & 1 & 109.4 & $10-19$ \\
\hline 5 & T. O. 1 mid module & 1 & 44 & $80-500$ \\
\hline 6 & T. O. $1 \mathrm{NTP}$ & 1 & $20-30$ & $100-800$ \\
\hline 7 & T. O. 1 shell fragment & 100 & $\begin{array}{l}\text { avg: } 0.3 \\
\max : 1.0\end{array}$ & 5 \\
\hline 8 & T. O. 1 structure fragment & 1 & 2 & 10 \\
\hline 9 & T. O. 1 structure fragment & 2 & 4 & 20 \\
\hline 10 & T. O. 1 structure fragment & 1 & 5 & 40 \\
\hline 11 & T. O. 2 module & 1 & $45-120$ & 400 \\
\hline 12 & T. O. 2 module & 1 & $45-120$ & 350 \\
\hline 13 & T. O. 2 module & 1 & 70 & 70 \\
\hline 14 & T. O. 2 NTP & 1 & $20-30$ & $100-800$ \\
\hline 15 & T. O. 2 debris & 10 & $0.1-1.0$ & 3 \\
\hline 16 & T. O. 2 debris & 10 & $0.1-1.0$ & 5 \\
\hline 17 & yaw TVC actuator & 1 & 7 & $27-71$ \\
\hline 18 & pitch TVC actuator & 1 & 7 & $27-71$ \\
\hline 19 & TVC electronics box & 1 & 9.5 & $16-43$ \\
\hline
\end{tabular}

Table 2: Fragment Classes Which Impact the Earth's Surface 


\section{Third Stage Impact Mode Categories}

The term "impact modes" is defined to include failure modes that result in impacts away from the intended target area as well as impacts within the normal target area. The mission flight safety officer (MFSO) will activate the FTS upon recognition that the trajectory has deviated from acceptable flight parameters and can soon endanger protected areas. This analysis assumes two delay times of three and four seconds between failure and FTS activation. The vehicle fragments that result will further disperse due to the relative velocity imparted by the dissipating motor energy, the relative velocity imparted by conversion of the original vehicle's angular velocity into translational velocity, and the varying aerodynamic characteristics of each fragment.

Failure scenarios that occur while the third stage is thrusting and which lead to impacts outside the nominal impact areas can be grouped into several categories:

1. Tumble Turn Failures. For an initially stable, exoatmospheric vehicle such as the STARS third stage, a tumble turn occurs when the line of action of the time averaged thrust vector is not aligned with the vehicle's mass center. This will occur when the vehicle autopilot is unable to stabilize the vehicle due to an electronic or mechanical failure. The resulting moment induces an angular acceleration and velocity: the vehicle begins to tumble. The amount to which the IIP deviates from the planned corridor is dependent upon the plane of the tumble (minimum deviation when the tumble plane is vertica', maximum when horizontal), the angular acceleration (the greater the angular acceleration, the sooner the integrated effect of the thrust vecior approaches zero), and the time between loss of vehicle control and FTS activation.

Three tumble turn subcategories have been identified. These deal with specific component failures, the discussion of which begins on page 13 .

1a. The nozzle gimbal angle returns to null (zero deflection, due to zero actuator force).

1b. The nozzle gimbal angle goes to its physical limits (hard over).

1c. The nozzle gimbal angle becomes fixed (stuck or frozen nozzle gimbal).

2. Controlled Turn Failures. Such a turn occurs when the autopilot is working properly, but the guidance commands to the autopilot are faulty. The result is a turn, potentially at maximum rate and acceleration, toward an incorrect target. It will be shown that the probability of such a chain of events occurring is quite low. If it should occur, the MFSO will activate the FTS upon recognition that the trajectory IIP is approaching protected areas.

3. Sudden Vehicle Destruction. The potential exists for the third stage to destruct while still within the normal range of trajectories. This could be due to rupture of the Orbus motor case, to failure of a system unrelated to the vehicle trajectory but upon which the MFSO is dependent for flight safety decisions, or to unintended activation of the FTS by either a system failure or human error. The vehicle fragments that result from such a destruct action will disperse somewhat from the IIP. 
4. Normal Dispersion. In addition to system failures, the potential exists for a vehicle which operates normally through third stage burn to impact away from the intended point. Causes for such a miss can be related to uncertainty in aerodynamics, winds, motor performance, and navigator errors. Of these, only the latter is likely to be detectable in time for the MFSO to take action. As will be shown, however, none are likely to cause a serious flight safety situation as long as the associated hazard area is accounted for in advance.

\section{Eailure Probabilities}

The probability that each type of failure might occur can be predicted by examination of the components which lead to the failure.

1. Tumble Turn Failure Probability. Failure of any one of a number of components can lead to a tumble turn. The overall probability of such a failure is $5.151 \times 10^{-4}$, based on the data given in Table 3. (These data and reference labels were extracted from the Abbott and Plowman report. $\left.{ }^{4}\right)$ For the reliability computation, the time duration $(\Delta t)$ of interest was taken to be 40 seconds, or 0.4 seconds longer than the nominal burn duration of the third stage Orbus motor. As noted below, the nature of the tumble turn will change depending on which component has failed. A probability for each type of tumble turn has been computed, based on the

\begin{tabular}{|c|l|c|}
\hline $\begin{array}{c}\text { Reference } \\
\text { Label }\end{array}$ & Component Description & $\begin{array}{c}\text { Failure Rate, QJ } \\
\left.\text { (per } 10^{6} \text { hours }\right)\end{array}$ \\
\hline \hline J1 & Electronics Battery & 10000.0 \\
\hline J2 & SANDAC V Battery & 10000.0 \\
\hline J3 & Electronics Power Distribution (MA180) & 1037.85 \\
\hline J4 & Rate Gyro & 200.0 \\
\hline J7 & SANDAC V Flight Computer & 1133.869 \\
\hline J11 & System Junction (MA173) & 239.836 \\
\hline J13 & Third Stage TVC & 3390.0 \\
\hline J19 & Third Stage TVC / Ignition Battery & 10000.0 \\
\hline J25 & ACS Electronics (MA176) & 8.207 \\
\hline J38 & IMU (Ring Laser) (MA726) & 360.4903 \\
\hline \hline $\begin{array}{l}\text { Overall } \\
\text { Reliability }\end{array}$ & $\prod^{e^{-Q_{j} \times \Delta t_{j}}=0.999485}$ \\
\hline
\end{tabular}

Table 3: Reliability of Components Which Could Cause a Tumble Turn 
responsible component reliability data. Some components have more than one failure mode, and so contribute to more than one type of tumble turn. To be conservative, the full failure rate for each such component has been allotted to each tumble turn probability calculation. This approach leads to an overestimation of the likelihood of a tumble turn, but avoids attempting to precisely allocate the probabilities of each distinct mode of failure for each component.

Failure of the items listed in Table 4 can cause loss of signal to the nozzle deflection actuators, causing the nozzle to return to the null (centered) position. For the M-1 mission, the nozzle must be deflected roughly $1^{\circ}$ in order to keep the thrust vector passing through the vehicle mass center during third stage burn. A failure which results in the third stage nozzle returning to the null position will produce a strong torque, a correspondingly high angular acceleration, and little deviation of the centroid of the impact points from the nominal IIP. The relative velocities between each fragment induced by both FTS activation and angular velocity prior to fragmentation can, however, cause impacts to disperse.

\begin{tabular}{|c|l|c|}
\hline $\begin{array}{c}\text { Reference } \\
\text { Label }\end{array}$ & Component Description & $\begin{array}{c}\text { Failure Rate, } \\
\text { (per } 10^{6} \text { hours) }\end{array}$ \\
\hline \hline $\mathrm{J} 1$ & Electronics Battery & 10000.0 \\
\hline $\mathrm{J} 2$ & SANDAC V Battery & 10000.0 \\
\hline $\mathrm{J} 3$ & Electronics Power Distribution (MA180) & 1037.85 \\
\hline $\mathrm{J} 7$ & SANDAC V & 1133.869 \\
\hline $\mathrm{J} 11$ & System Junction (MA173) & 239.836 \\
\hline $\mathrm{J} 19$ & Third Stage TVC / Ignition Battery & 10000.0 \\
\hline $\mathrm{J} 38$ & IMU (Ring Laser) (MA726) & 360.4903 \\
\hline \hline \multicolumn{2}{|c|}{ Overall Reliability $=0.99965011$} \\
\hline
\end{tabular}

Table 4: Component Reliability Potentially Related to a Null-Positioned Nozzle Failure

Similarly, failure of the items listed in Table 5 can cause the actuators to deflect the nozzle hard against its mechanical limits. Again, a fast tumble will be the result.

If the items listed in Table 6 were to fail, the inputs to the TVC electronics would remain fixed at their most recent value. Hence, the nozzle would also remain fixed at that point. For this situation, the nozzle is likely to be positioned such that the thrust vector passes very nearly through the mass center of the vehicle. Hence, tumble rates will build slowly and will still be low at the time of FTS activation.

2. Controlled Turn Failure Probability. For a controlled turn to occur, the autopilot software which stabilizes the vehicle (and runs on the SANDAC V flight computer) must be operating properly (otherwise, a tumble turn will result). In order for the autopilot to function properly, 


\begin{tabular}{|c|l|c|}
\hline $\begin{array}{c}\text { Reference } \\
\text { Label }\end{array}$ & Component Description & $\begin{array}{c}\text { Failure Rate, QJ } \\
\text { (per } 10^{6} \text { hours) }\end{array}$ \\
\hline \hline J3 & Electronics Power Distribution (MA180) & 1037.85 \\
\hline J4 & Rate Gyro & 200.0 \\
\hline J7 & SANDAC V & 1133.869 \\
\hline J11 & System Junction (MA173) & 239.836 \\
\hline J13 & Third Stage TVC & 3390.0 \\
\hline J25 & ACS Electronics (MA176) & 8.207 \\
\hline J38 & IMU (Ring Laser) (MA726) & 360.4903 \\
\hline \hline \multicolumn{2}{|c|}{ Overall Reliability $=0.99992922$} \\
\hline
\end{tabular}

Table 5: Component Reliability Potentially Related to a Hard-over Nozzle Failure

\begin{tabular}{|c|l|c|}
\hline $\begin{array}{c}\text { Reference } \\
\text { Label }\end{array}$ & Component Description & $\begin{array}{c}\text { Failure Rate, QJ } \\
\left.\text { (per } 10^{6} \text { hours }\right)\end{array}$ \\
\hline \hline $\mathrm{J} 7$ & SANDAC V & 1133.869 \\
\hline $\mathrm{J} 11$ & System Junction (MA173) & 239.836 \\
\hline \multicolumn{2}{|c|}{ Overall Reliability = 0.99998473 } \\
\hline
\end{tabular}

Table 6: Component Reliability Potentially Related to a Stuck Nozzle Failure

the vehicle angular rates measured by the IMU must be correct (or very nearly so). A controlled turn results from either a grossly incorrect position or velocity being computed by the navigator software, or an incorrect steering command being generated by the guidance software. Both of these functions are resident on a single processor board on the SANDAC, and are successfully tested thousands of times under conditions ranging from nominal to extremeiy off nominal. A SANDAC hardware failure, due, for example, to radiation, could in theory cause such an error if one or more appropriate memory locations were damaged. A conservative bound on such errors can be computed by assuming all failures of a SANDAC processor board are of the type required to generate a controlled turn. In addition, for this calculation it is assumed that all IMU failures are small enough not to cause instability, yet are sufficient to cause a controlled turn. The failure rate of a SANDAC processor board is 155.470 failures per $10^{6}$ hours and for the IMU is 360.4903 failures per $10^{6}$ hours. ${ }^{4}$ Therefore, the combined reliability of these components during the 40 second burn of the third stage motor is given by 


$$
e^{-\left(\frac{155.470 \times 40}{3600 \times 10^{6}}\right)} \times e^{-\left(\frac{360.4903 \times 40}{3600 \times 10^{6}}\right)}=0.999994267 \text {, and the likelihood of a controlled turn }
$$

failure is bounded by $5.733 \times 10^{-6}$. Under the conservative assumption that 10 percent of the reachable surface area (for several seconds of IIP propagation from a nominal point) of the earth has been designated as a protected area, the probability of impacting in such an area becomes $5.733 \times 10^{-7}$ (at most). Since the probability of a controlled turn, obtained using the described conservative assumptions, is significantly smaller than the probability of the other failure modes, controlled turn failures were not addressed further. It will be shown that the more likely failure modes produce very small expected casualty and probability of land impact numbers. The controlled turn numbers are not significant additions.

3. Sudden Vehicle Destruction Probability. The Orbus (third stage) motor case failure rate is 360903 per $10^{6}$ hours, which equates to a failure probability of $4.002 \times 10^{-3}$ over the 40 second burn duration of the motor. ${ }^{4}$ The probability of premature FTS activation has been computed to be $1.0 \times 10^{-7}$ due to onboard hardware failures. ${ }^{12}$ The probabilities of failure of onboard systems which are unrelated to the trajectory but essential to MFSO monitoring of the trajectory are also available. A rigorous estimation of the likelihood of ground based system failure, or of human error causing FTS activation, is beyond the scope of this report. However, a value of 0.01 ( 1 flight termination in 100 flights) has been assigned. It will be shown (compare Figure 7 with Figure 9) that using a value of even 1.0 changes the expected impact density results only in the immediate region of the nominal IIP trace. This is to be expected since for this scenario the vehicle will be operating correctly up to the point of a ground system related failure. A summary of the component failure rates for sudden vehicle destruct is shown in Table 7.

\begin{tabular}{|c|l|c|}
\hline $\begin{array}{c}\text { Reference } \\
\text { Label }\end{array}$ & Component Liscription & $\begin{array}{c}\text { Likelihood of } \\
\text { Failure }\end{array}$ \\
\hline \hline S3C & Third Stage Motor Case & $4.002 \times 10^{-3}$ \\
\hline PFTS & $\begin{array}{l}\text { Premature FTS Firing due to On-Board } \\
\text { Systems }\end{array}$ & $1.0 \times 10^{-7}$ \\
\hline BTM & Weak FTS Battery or Loss of TM Signal & $1.11 \times 10^{-4}$ \\
\hline GSE & Ground System (and related) Error & $1.0 \times 10^{-2}$ \\
\hline \hline
\end{tabular}

Table 7: Reliability of Components For Which Failure Results in Sudden Vehicle Destruction

12. Blankenau, S. J. (7222), Reliability Predictions for the STARS Destruct System, memo to T. L. Downey (7525) dated May 12, 1989. 
4. Normal Dispersion. Dispersions in the target area following a normal flight have also been considered. Factors which cause these dispersions include motor performanie variations, guidance system tolerances, winds, and aerodynamic variations. These factors have been included in the impact density calculations, and, for conservatism, the probability of a normal flight has been assumed to be one. (Note that this is in addition to the probabilities of impact due to failure-mode flights, as discussed above.)

A summary of the probability of each event category that lead to impacts in the downrange area is given in Table 8 . A failure probability may be computed from reliability data as simply 1 minus the reliability value.

\begin{tabular}{|c|c|}
\hline Failure mode & Probability of Event Occurrence \\
\hline \hline Nozzle gimbal hard-over (tumble turn) & $7.07773 \times 10^{-5}$ \\
\hline Nozzle gimbal at null (tumble turn) & $3.49884 \times 10^{-4}$ \\
\hline Nozzle gimbal stuck (tumble turn) & $1.52631 \times 10^{-5}$ \\
\hline Controlled turn & $5.7328 \times 10^{-6}$ \\
\hline Sudden vehicle destruct & 0.0141311 \\
\hline Normal flight to target area & 1.0 \\
\hline \hline $\begin{array}{c}\text { Note that the sum of these probabilities is greater than one, due to the use } \\
\text { of conservative assumptions in the derivation of each one }\end{array}$ \\
\hline
\end{tabular}

Table 8: Probability of Events Which Lead to Impacts in the Downrange Area.

\section{Tumble Turn Simulations}

For tumble turns, sudden vehicle destruct, and normally concluded flights, estimates of the third stage assembly state vector at various times have been computed using a Monte Carlo approach. This was accomplished using the failure variation preprocessing code MCPRAM ${ }^{13}$ (Monte Carlo Preprocessor for AMEER) with the trajectory code AMEER ${ }^{14}$ (Aero Mechanical Equation Evaluation Routines) and the fragmentation preprocessing code SAFETIE ${ }^{15}$ (Sandia Analysis of Fragment Trajectories). MCPRAM was developed for fuze effectiveness studies and uses Monte Carlo techniques to produce input files of multiple trajectories for AMEER to solve. MCPRAM allows any standard AMEER input variable to be varied about a designated mean with either a uniform or

13. LaFarge, Robert A., A Users' Manual for MCPRAM and for the Fuze Options in AMEER, SAND90-0483, May, 1990.

14. Meyer, Eugene J., A User's Manual for the AMEER Flight Path Trajectory Simulation Code, SAND802056, December, 1984.

15. LaFarge, Robert A., Using Monte Carlo Techniques and Parallel Processing for Fragmentation Analysis of Explosive Payloads, AIAA 92-0653, January, 1992. 
normal distribution. MCPRAM also allows for arbitrarily sized groups of correlated parameters to be randomly varied. A covariance matrix is used to model the correlation among the parameters.

For the tumble turn analysis, two approaches were used to generate fragment impact distributions. Both used MCPRAM and AMEER to compute the position and velocity of the third stage after each specified failure mode and after a specified delay time (either 3 or 4 seconds) before activating the FTS. In addition to the tumble turn failure modes, the instantaneous flight termination (zero delay time) and normal flight completion scenarios were also investigated. This information was used by SAFETIE1 as initial conditions for that portion of the analysis that investigates the effects of FTS activation and dispersion due to the atmosphere. The resulting state vectors were used by SAFETIE1 to produce initial conditions to AMEER for computing trajectories to investigate the effects of FTS activation and dispersion due to the atmosphere.

In the first approach used for impact point generation, covariance matrices that model the uncertainties in the third stage nominal position and velocity were included. The covariance matrices were generated from data obtained froni a study of the effects on the trajectory of $3 \sigma$ variations of certain parameters such as propellent weight, specific impulse, and thrust factor. ${ }^{16}$ Additionally, the rocket motor nozzle deflection angles were varied to simulate the three types of failure modes under investigation, i.e., stuck nozzle, return to the null position nozzle, and an arbitrary direction, hard-over nozzle. Each failure mode and each delay time generated a separate impact distribution.

The second approach eliminated the initial-state covariances matrices. The resulting impact distributions can be used to produce impact areas about the nominal trajectory. These ellipses can be superimposed over the current trajectory in a real-time flight safety software system to help the MFSO determine if the FTS should be activated.

\section{Statistical Modeling of the Eailure Modes}

For each of the tumble turn failure modes, the nozzle deflection angles were either kept constint or were varied with uniform or normal distributions. The variable PHMTRD is the angle which defines the plane of the nozzle deflection in roll, and the variable XIMTRD is the angle of deflection from the longitudinal vehicle axis. To simulate the hard-over nozzle gimbal angle failure mode, XIMTRD was given a constant value of 3.0 degrees (a conservatively small estimate of the physical limitation of the Orbus nozzle), and PHMTRD was given a uniform distribution between 0 and 360 degrees. To simulate the nozzle gimbal return to the null failure mode, XIMTRD was given a normal distribution with a mean of 0 degrees and a standard deviation of 0.27 degrees. ${ }^{17}$ PHMTRD was given a uniform distribution between 0 and 180 degrees. In both models, the nominal mass center offsets were included in the analysis. For the stuck nozzle gimbal failure mode, the relevant parameter is the offset of the thrust vector from the center of mass, not the actual noz-

16. Study performed by John White of the Sandia National Laboratories Navigation. Guidance, and Control System Department.

17. This standard deviation estimate is based on changes in the nozzle null orientation due to motor case flexibility under operational pressures. 
zle gimbal angle. To simplify the calculations, the mass asymmetries were removed so that the nozzle angle that produces a null thrust moment would not have to be computed at each time of the analysis. XIMTRD was given a normal distribution with a mean of 0 degrees and a standard deviation of 0.02 degrees, ${ }^{18}$ and PHMTRD was given a uniform distribution between 0 and 180 degrees. For each failure mode, 151 random trajectories were computed at each one-second increment along the trajectory from 18 seconds to 38 seconds after third stage ignition. For each failure mode, a post-processor was used to extract (from the nominal AMEER output file) the file of 3171 $((38-18+1) \times 151)$ state vectors for each specified delay time. These state vectors were used as initial conditions for the SAFETIE1 portion of the analysis. The effects of each of the tumble turn failure modes were investigated for the both with and without initial state variation. A total of fourteen files of 3171 state vectors were produced for this analysis.

\section{Fragment Impact Distribution}

For a given tumble turn analysis approach, failure mode, and delay time, SAFETIE1 assumed that the file of 3171 state vectors describes the position, velocity, angular orientation, and angular velocity of the third stage assembly at the time of FTS activation. For each of the seven initial fragment classes ${ }^{19}$ a random incremental velocity was computed, based on the statistical models in Table 1 . The total velocity vector of each fragment was computed by adding the incremental velocity vector and $\bar{V}_{\omega}$ (the velocity vector caused by the angular velocity of the third stage assembly) to the velocity vector of the third stage assembly before FTS activation. The velocity vector $\bar{V}_{\omega}$ is computed by taking the vector cross product of the third stage angular velocity and the vector describing the difference in location between the third stage $\mathrm{cg}$ and the $\mathrm{cg}$ of the appropriate fragment. Aerothermal/structural analysis has indicated that the two payloads and the third stage booster would breakup near 150000 feet altitude. The trajectory simulations included this further fragmentation, resulting in the 19 fragment classes and associated trajectories (shown in Table 2 on page 11) from that altitude down to impact.

A total of 843486 trajectories were computed. ${ }^{20}$ Each fragment was modeled as a point mass in AMEER with an appropriate drag model (tumbling cube, tumbling cylinder, or the payload). The Kwajalein annual statistical wind model was used in all the trajectories. ${ }^{21}$ For a given altitude, the wind model uses five statistical parameters. In Cartesian coordinates, these parameters are the means and standard deviations of the two orthogonal wind velocity components and the correlation coefficient between the two components. All 19 fragments from a given FTS action fall through

18. This standard deviation estimate is derived from the time history of the offset of the thrust vector relative to the vehicle mass center when the gimbal is actively controlled.

19. Defined in Table 1:Two thrust vector activators, 1 TVC electronics package, 1 motor aft dome nozzle, 2 payloads, and 1 third stage booster.

20. $843486=(19 \times((2 \times 3)+1) \times 3171 \times 2): 19$ fragment classes, 2 destruct delay times, 3 tumble turn failure modes, 1 sudden destruct failure mode, 3171 time-of-destruct state vectors, with and without pre-failure state vector variations.

21. Kwajalein Missile Range, Kwajalein, Marshall Islands, Range Reference Atmosphere, 0 - $70 \mathrm{~km}$ Altitude, Document 360-82, published by Range Commanders Council. White Sands Missile Range, New Mexico. 
the same $v$ ind profile. The impact distributions for the initial state vector covariance approach are shown in Figures 1-7, and the impact distributions which result from failures off the nominal trajectory are shown in Figures 8-14.

\section{Computation of the Impact Density Map}

The impact data generated using Monte Carlo techniques can be used to develop a statistical model of the impact likelihood on the earth's surface. The statistical model is built up from subsets of the impact data, where each subset consists of all the impacts resulting from a given combination of the systematically varied impact mode parameters. For impacts resulting from failures, the systematically varied impact mode parameters are the failure time, the fragment class, the failure type, and the delay time between the failure and FTS activation. One hundred fifty-one (151) impacts were generated for each subset by the Monte Carlo technique described previously. For normally completed flights, only the fragment class is systematically varied. One thousand one (1001) impacts were generated for each subset of normally completed flights.

For the discussion which follows, analysis of impacts from normally completed flights is a subset of the analysis applied to failure mode impacts. When the differences are not obvious, they will be noted explicitly.

The impact points vary due to the random variations in failure-time state vector, the nozzle position (see page 18), the fragment velocities (induced by both FTS activation and the angular velocity which results from a tumble turn), and the wind profile. Since two or more of these variations are Gaussian in nature, it can be expected that for each such subset the impact point variations will also approximate a Gaussian distribution. Hence, for each such subset, five parameters describing the correspondirig Gaussian impact point distribution function are computed: mean longitude and latitude, standard deviations in longitude and latitude, and the correlation coefficient reiating deviations from the mean in longitude with those in latitude. This function describes the impact probability density function (PDF) given that the prescribed conditions 22 are valid.

The equations for the defining parameters for the functions are given in Table $9 . \lambda_{i}$ is the $i^{\text {th }}$ impact longitude of the subset, $\delta_{i}$ is the $i^{\text {th }}$ impact latitude of the subset, and $n$ is the number of impact points in the subset. The value of the PDF function at an arbitrary longitude, $\lambda$, and latitude, $\delta$, is given by the bivariate Gaussian density function, as shown in Table 10 . Note that it is an exponential function of the five defining parameters given in Table 9. To obtain the impact density function for all combinations of the time of failure, fragment class, and type of failure, the subset PDFi are combined numerically in the following manner.

First, a grid of latitude-longitude points in the area of interest is defined. The number of impacts per unit area is computed at each of the grid points. For each grid point and combination of impact mode and fragment class, the density of impacts expected for all times of the impact mode is ob-

22. Failure time, fragment class. failure type, and delay time between failure and FTS activation 


\begin{tabular}{|l|l|}
\hline mean longitude & $\bar{\lambda}=\frac{1}{n} \sum_{i=1}^{n} \lambda_{i}$ \\
\hline mean latitude & $\bar{\delta}=\frac{1}{n} \sum_{i=1}^{n} \delta_{i}$ \\
\hline standard deviation of longitude & $\sigma_{\lambda}=\sqrt{\frac{1}{n-1} \sum_{i=1}^{n}\left(\lambda_{i}-\bar{\lambda}\right)^{2}}$ \\
\hline standard deviation of latitude & $\sigma_{\delta}=\sqrt{\frac{1}{n-1} \sum_{i=1}^{n}\left(\delta_{i}-\bar{\delta}\right)^{2}}$ \\
\hline correlation coefficient & $\rho_{\lambda \delta}=\frac{\sum_{i=1}^{n}\left[\left(\lambda_{i}-\bar{\lambda}\right)\left(\delta_{i}-\bar{\delta}\right)\right]}{\sqrt{\sum_{i=1}^{n}\left(\lambda_{i}-\bar{\lambda}\right)^{2}} \sqrt{\sum_{i}^{n}\left(\delta_{i}-\bar{\delta}\right)^{2}}}$ \\
\hline
\end{tabular}

Table 9: The Defining Parameters for the Impact Probability Density Functions

$$
p d f(\lambda, \delta)=\frac{e^{\left\{\frac{-1}{2\left(1-\rho_{\lambda \delta}^{2}\right)}\left[\frac{(\lambda-\bar{\lambda})^{2}}{\sigma_{\lambda}^{2}}-\frac{2 \rho_{\lambda \delta}(\lambda-\bar{\lambda})(\delta-\bar{\delta})}{\sigma_{\lambda} \sigma_{\delta}}+\frac{(\delta-\bar{\delta})^{2}}{\sigma_{\delta}^{2}}\right]\right\}}}{2 \pi \sigma_{\lambda} \sigma_{\delta} \sqrt{1-\rho_{\lambda \delta}^{2}}}
$$

Table 10: The Bivariate Gaussian Density Function for the Impact Probability Density Functions

tained. This is done for failure impact modes by numerically integrating in time the value of the PDFs obtained for each subset described above at the grid point, and multiplying the integrand with the likelihood of the failure occurring over the time interval of integration and by the number of pieces in the given fragment class. For the normal mission completion impact mode, integration over time is not necessary since no time variation is relevant. Instead, the subset PDF is evaluated at the grid point and multiplied by the likelihood of normal mission completion and by the number of pieces in the given fragment class. The result is summed with similar results for all other combinations of impact mode and fragment class. This sum is the number of impacts per unit area which can be expected at the grid point from all impact modes. 


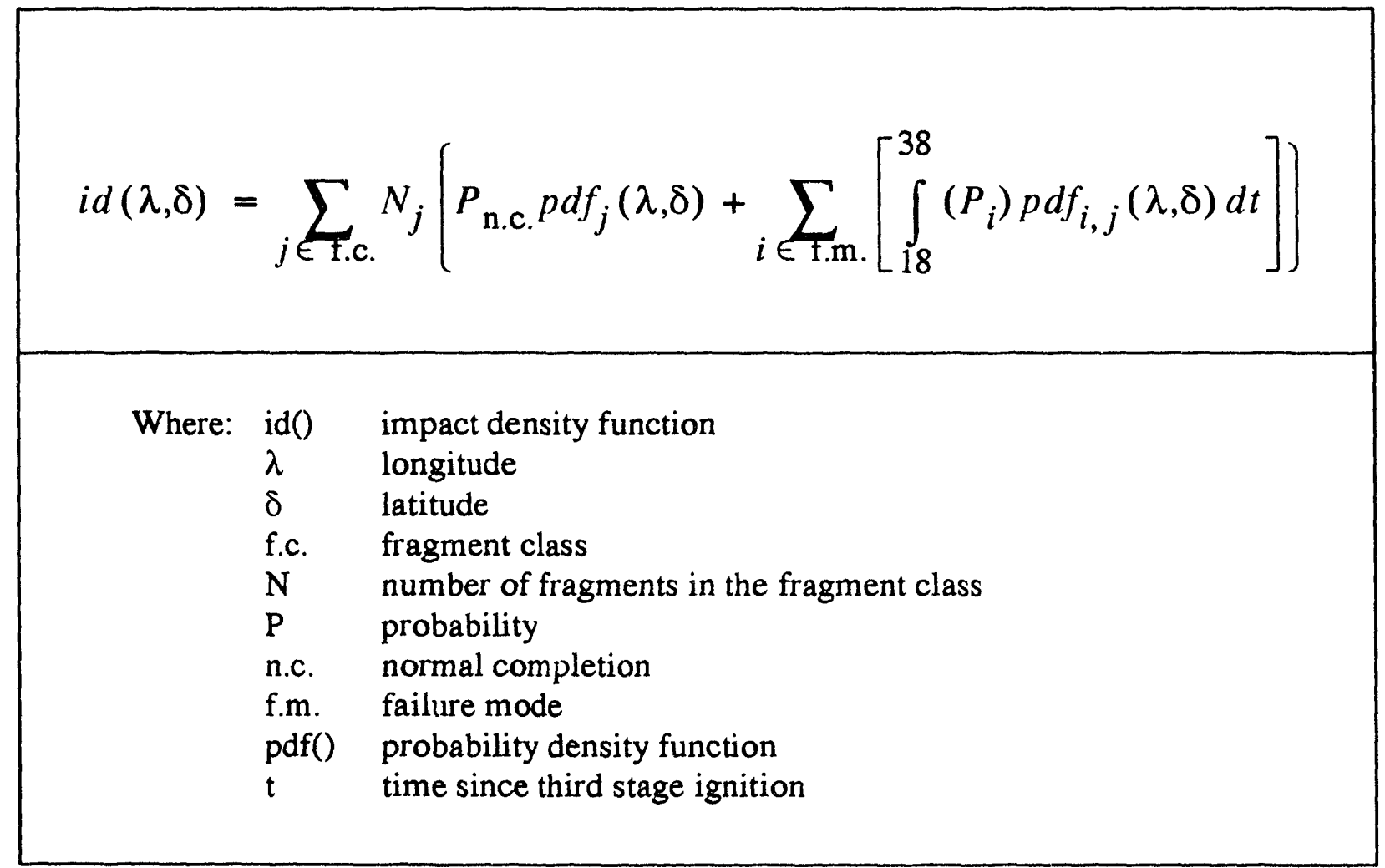

Table 11: The Impact Density Function for an Arbitrary Longitude and Latitude

This process is repeated for every point in the grid for each delay time of interest. The results are plotted as a contour plot with independent axes of longitude and latitude. These contours are plotted in Figure 7 for the 3 second FTS delay and Figure 8 for the 4 second FTS delay.

To demonstrate that the (unknown) likelihood of FTS activation by ground system error does not greatly affect the contour lines less than $10^{-6}$, the data has been recalculated with the spontaneous destruct probability of 1.0 . (This is in contrast to the value of 0.0141311 used for all other calculations, and discussed on page 16). The corresponding plots are given in Figure 9 and Figure 10.

A similar technique is used to compute the probability of land impact, the expected casualty $\left(\mathrm{E}_{\mathrm{c}}\right)$ value for each island (Tables 12 and 13), and the probability of an impact in the various keep-out zones (Table 14). The Gaussian impact distribution functions used to compute the data for the contour plots are used to compute the number of impacts per unit area expected at points within populated land areas and keepout zones. The expected casualty values assume all fragments are hazardous, that each person occupies a distinct 32 square feet area, and that an impact within such an area causes a casualty. Land impact calculations multiply the number of impacts per unit area by the land area of interest. The expected number of impacts within a keepout zone is computed by integrating the point values of the number of impacts per unit area over the area of the keepout zones. 


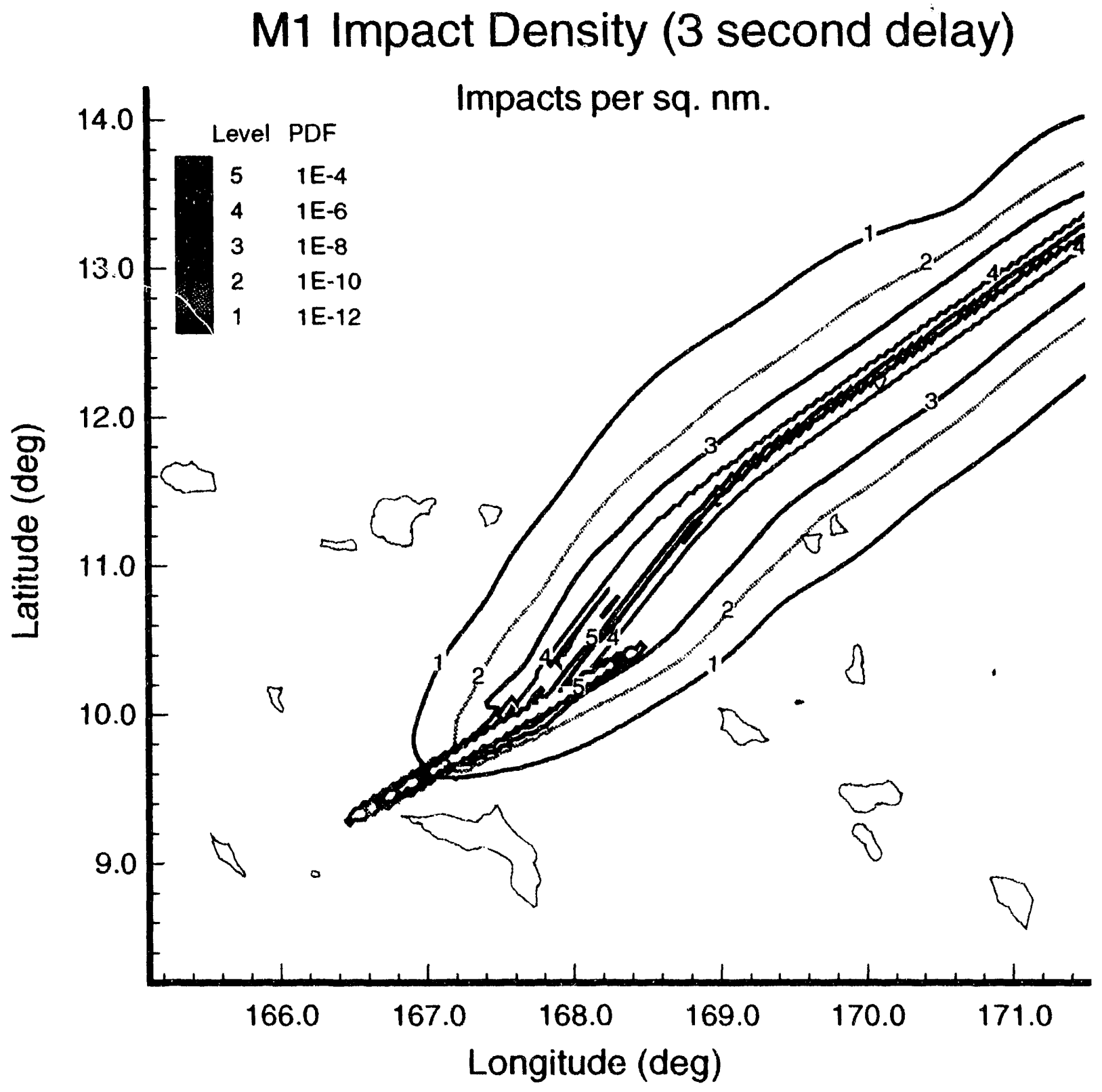

Figure 7: Impact Density Map: 3 Second Delay Between Failure and FTS Activation 


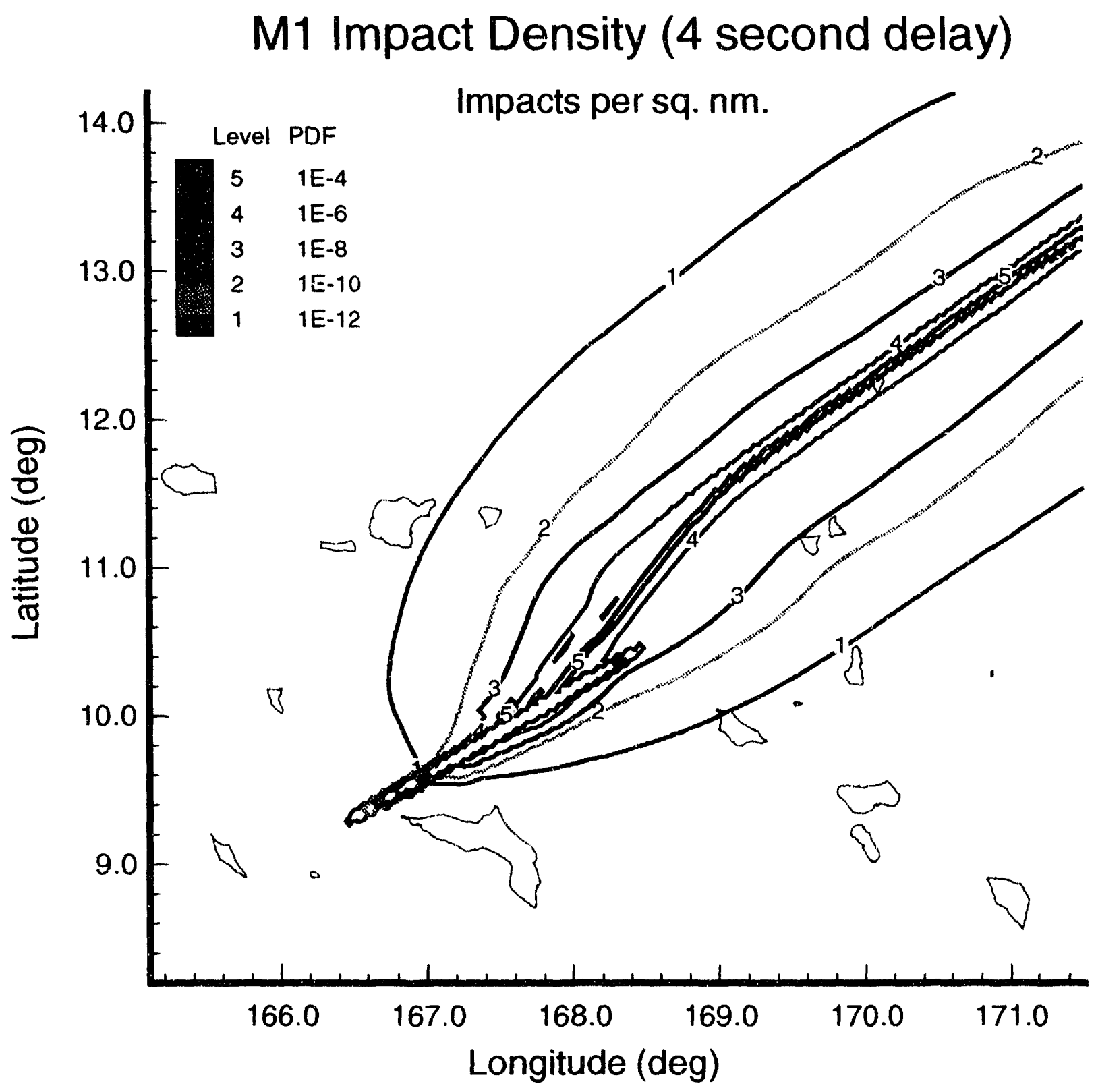

Figure 8: Impact Density Map: 4 Second Delay Between Failure and FTS Activation 


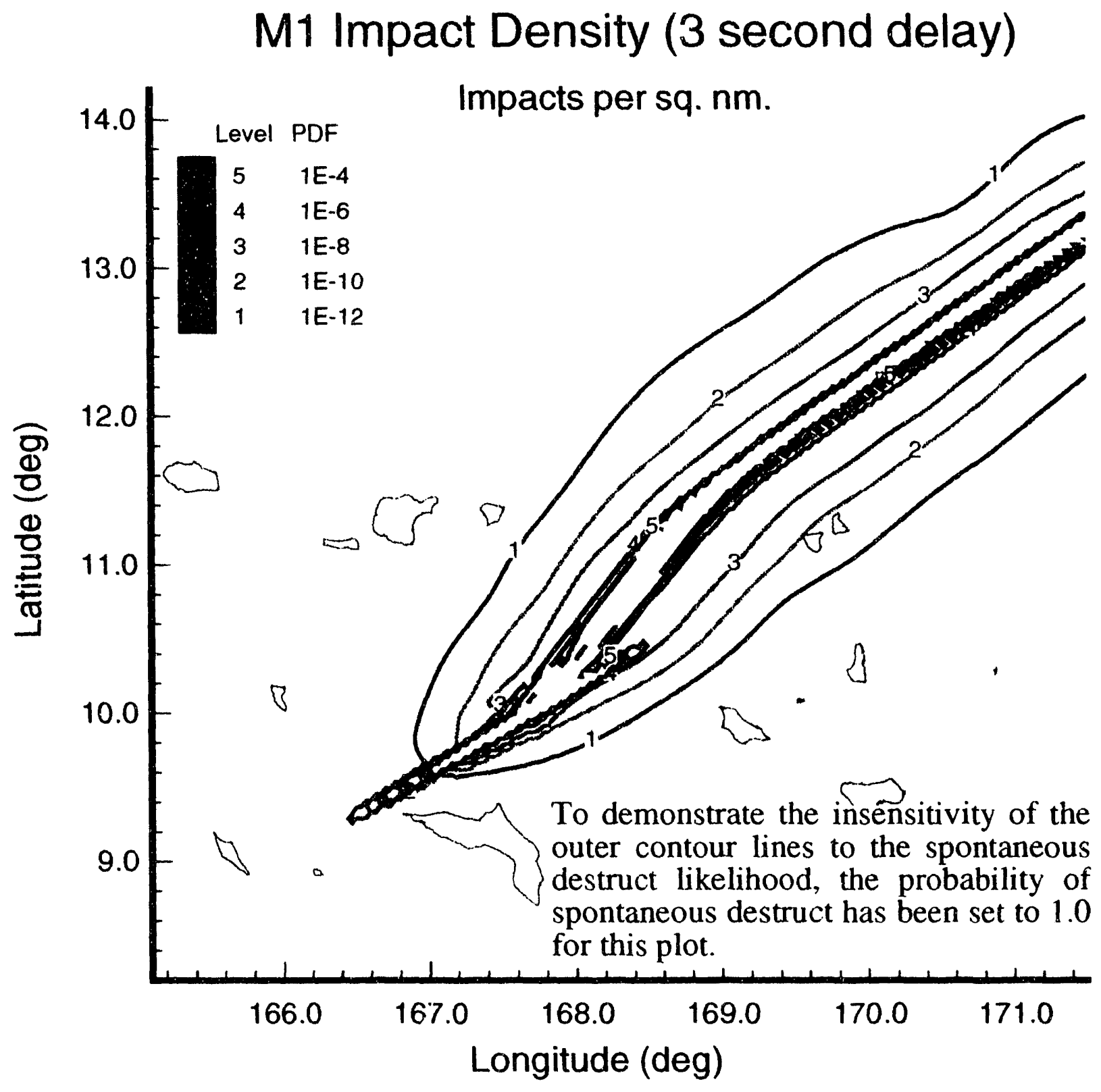

Figure 9: Impact Density Map: 3 Second Delay Between Failure and FTS Activation, Spontaneous Destruct Probability $=1.0$ 


\section{M1 Impact Density (4 second delay)}

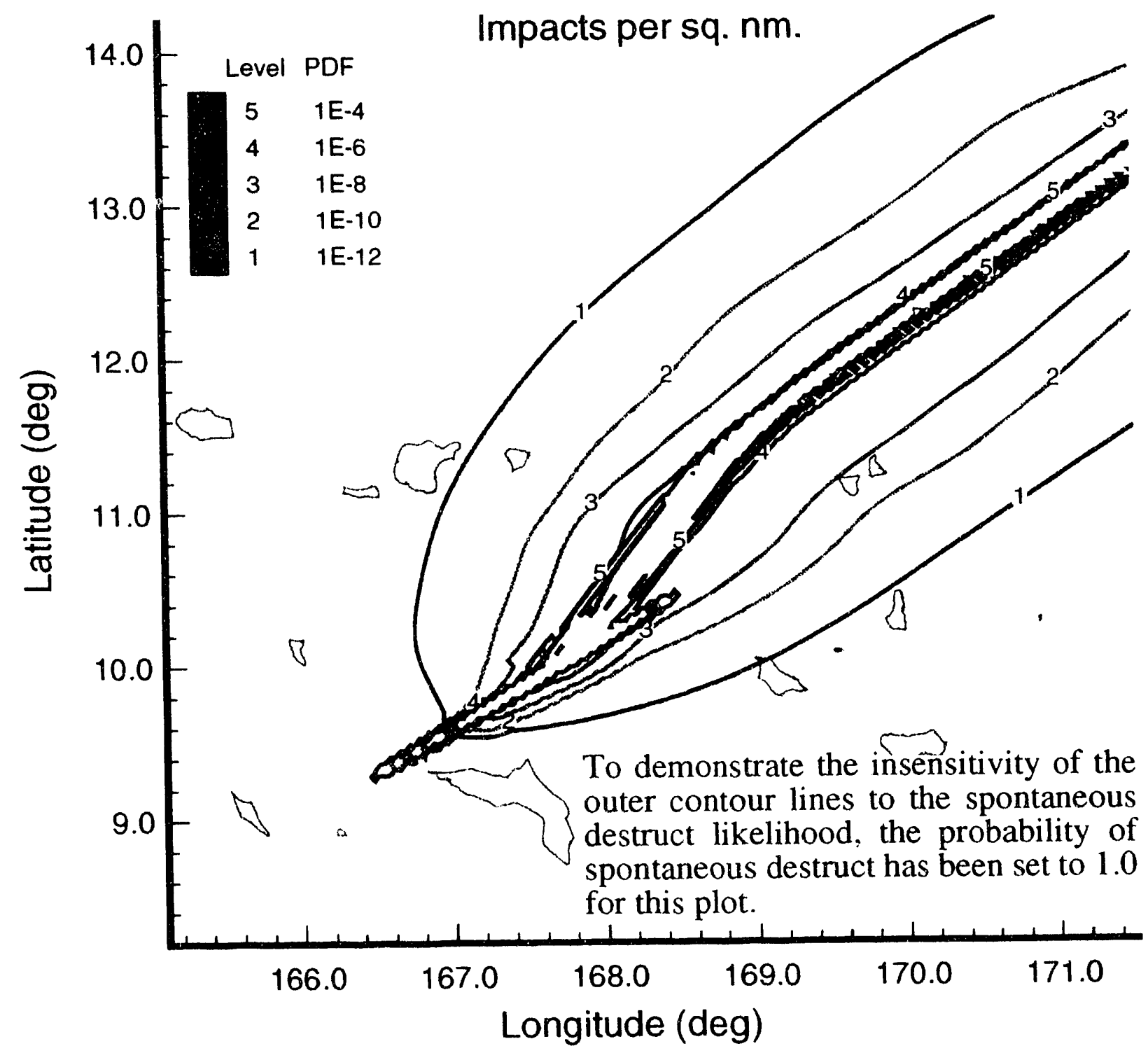

Figure 10: Impact Density Map: 4 Second Delay Between Failure and FTS Activation, Spontaneous Destruct Probability $=1.0$ 
Mission Hazard Assessment for STARS Mission 1 (M1) in the Marshall Islands Area

Table 12: Land Impact Probabilities and Expected Casualties: 3 Second FTS Delay

\begin{tabular}{|c|c|c|c|c|c|c|}
\hline \multirow{2}{*}{ Name } & Land Area & N. Lat & E. Long & \multirow{2}{*}{ Population } & \multirow{2}{*}{$\begin{array}{l}\text { Land Impact } \\
\text { Probability }\end{array}$} & \multirow{2}{*}{$\begin{array}{l}\text { Expected } \\
\text { Casualties }\end{array}$} \\
\hline & sq. nm. & deg. & deg. & & & \\
\hline \multicolumn{7}{|c|}{ Ailinginae Atoll } \\
\hline Majokoryaan & 0.118 & 11.1320 & 166.5270 & 0 & $2.92074 \times 10^{-22}$ & 0 \\
\hline \multicolumn{7}{|l|}{ Bikar Atoll } \\
\hline Bikar & 0.065 & 12.1862 & 170.1033 & 0 & $8.57815 \times 10^{-08}$ & 0 \\
\hline \multicolumn{7}{|l|}{ Bikini Atoll } \\
\hline Bikini & 0.632 & 11.6277 & 165.5458 & 0 & $1.73412 \times 10^{-35}$ & 0 \\
\hline \multicolumn{7}{|l|}{ Ailuk Atoll } \\
\hline Ailuk & 0.204 & 10.217 & 169.982 & 465 & $6.91392 \times 10^{-20}$ & $1.36598 \times 10^{-22}$ \\
\hline Enijabro & 0.145 & 10.4504 & 169.9563 & 3 & $7.42574 \times 10^{-18}$ & $1.33165 \times 10^{-22}$ \\
\hline Kapen & 0.223 & 10.4588 & 169.9500 & 4 & $1.42945 \times 10^{-17}$ & $2.2224 \times 10^{-22}$ \\
\hline \multicolumn{7}{|l|}{ Erikub Atoll } \\
\hline Erikub & 0.136 & 9.0200 & 170.0616 & 0 & $1.47325 \times 10^{-35}$ & 0 \\
\hline \multicolumn{7}{|c|}{ Kwajalein Atoll } \\
\hline Big Bustard & 0.009 & 8.762 & 167.739 & 7 & $5.14455 \times 10^{-29}$ & $3.46817 \times 10^{-32}$ \\
\hline Biggerann & 0.152 & 9.337 & 167.060 & 12 & $7.35192 \times 10^{-17}$ & $5.03079 \times 10^{-21}$ \\
\hline Ebadon & 0.350 & 9.328 & 166.827 & 38 & $5.40554 \times 10^{-17}$ & $5.08689 \times 10^{-21}$ \\
\hline Ebeye & 0.088 & 8.780 & 167.739 & 8500 & $1.18378 \times 10^{-27}$ & $9.91072 \times 10^{-29}$ \\
\hline Ebioaji & 0.023 & 8.836 & 167.740 & 10 & $4.22309 \times 10^{-27}$ & $1.59148 \times 10^{-30}$ \\
\hline Eniwetak & 0.018 & 9.017 & 167.716 & 4 & $1.23805 \times 10^{-23}$ & $2.38464 \times 10^{-27}$ \\
\hline Ennubirr & 0.038 & 9.366 & 167.496 & 380 & $2.97965 \times 10^{-17}$ & $2.58264 \times 10^{-19}$ \\
\hline Ennylabegan & 0.155 & 8.799 & 167.618 & 98 & $1.97824 \times 10^{-26}$ & $1.0841 \times 10^{-29}$ \\
\hline Enubuj & 0.105 & 8.749 & 167.685 & 60 & $6.0313 \times 10^{-28}$ & $2.98724 \times 10^{-31}$ \\
\hline Gagan & 0.009 & 9.288 & 167.538 & 8 & $5.14867 \times 10^{-19}$ & $3.9668 \times 10^{-22}$ \\
\hline Gellinam & 0.009 & 9.099 & 167.729 & 6 & $1.47324 \times 10^{-22}$ & $8.51295 \times 10^{-26}$ \\
\hline
\end{tabular}


Mission Hazard Assessment for STARS Mission 1 (M1) in the Marshall Islands Area

Tabie 12: Land Impact Probabilities and Expected Casualties: 3 Second FTS Delay

\begin{tabular}{|c|c|c|c|c|c|c|}
\hline \multirow{2}{*}{ Name } & Land Area & N. Lat & E. Long & \multirow{2}{*}{ Population } & \multirow{2}{*}{$\begin{array}{l}\text { Land Impact } \\
\text { Probability }\end{array}$} & \multirow{2}{*}{$\begin{array}{l}\text { Expected } \\
\text { Casualties }\end{array}$} \\
\hline & sq. $\mathrm{nm}$. & deg. & deg. & & & \\
\hline Gugeegue & 0.073 & 8.849 & 167.744 & 10 & $2.33017 \times 10^{-26}$ & $2.7667 \times 10^{-30}$ \\
\hline Kwajalein & 0.948 & 8.723 & 167.737 & 3446 & $8.55125 \times 10^{-28}$ & $2.69423 \times 10^{-30}$ \\
\hline Legan & 0.035 & 8.984 & 167.579 & 6 & $2.2085 \times 10^{-23}$ & $3.28155 \times 10^{-27}$ \\
\hline $\begin{array}{c}\text { Little } \\
\text { Bustard }\end{array}$ & 0.003 & 8.755 & 167.737 & 5 & $1.25703 \times 10^{-29}$ & $1.81591 \times 10^{-32}$ \\
\hline Meck & 0.047 & 9.003 & 167.727 & 255 & $1.60705 \times 10^{-23}$ & $7.55735 \times 10^{-26}$ \\
\hline Omelek & 0.012 & 9.050 & 167.743 & 1 & $2.40882 \times 10^{-23}$ & $1.73989 \times 10^{-27}$ \\
\hline Roi-Namur & 0.510 & 9.396 & 167.476 & 470 & $1.04913 \times 10^{-15}$ & $8.38023 \times 10^{-19}$ \\
\hline \multicolumn{7}{|l|}{ Lae Atoll } \\
\hline Lae & 0.230 & 8.921 & 166.264 & 192 & $1.78428 \times 10^{-24}$ & $1.29102 \times 10^{-27}$ \\
\hline Lib Island & 0.230 & 8.3160 & 167.3800 & 140 & $8.19832 \times 10^{-36}$ & $4.32537 \times 10^{-39}$ \\
\hline \multicolumn{7}{|l|}{ Likiep Atoll } \\
\hline Jibal & 0.156 & 9.888 & 169.276 & 70 & $8.61484 \times 10^{-19}$ & $3.35057 \times 10^{-22}$ \\
\hline Lado & 0.189 & 9.8425 & 169.3105 & 20 & $2.22582 \times 10^{-19}$ & $2.04154 \times 10^{-23}$ \\
\hline Likeip & 0.510 & 9.823 & 169.303 & 406 & $4.19976 \times 10^{-19}$ & $2.89786 \times 10^{-22}$ \\
\hline Mato & 0.461 & 10.044 & 168.997 & 30 & $2.1596 \times 10^{-15}$ & $1.21812 \times 10^{-19}$ \\
\hline Mero & 0.148 & 9.895 & 169.265 & 60 & $1.11568 \times 10^{-18}$ & $3.92037 \times 10^{-22}$ \\
\hline \multicolumn{7}{|c|}{ Maleolap Atoll } \\
\hline Airik & 0.204 & 8.5033 & 171.1980 & 220 & $7.85052 \times 10^{-55}$ & $7.33819 \times 10^{-58}$ \\
\hline Kaven & 0.612 & 8.8983 & 170.8460 & 95 & $2.96082 \times 10^{-43}$ & $3.98367 \times 10^{-47}$ \\
\hline Ollot & 0.102 & 8.7708 & 171.1810 & 80 & $8.09349 \times 10^{-50}$ & $5.50204 \times 10^{-53}$ \\
\hline Tar & 0.081 & 8.8383 & 171.0967 & 29 & $9.1814 \times 10^{-48}$ & $2.84918 \times 10^{-51}$ \\
\hline Tjan & 0.102 & 8.9075 & 170.8950 & 0 & $2.35394 \times 10^{-44}$ & 0 \\
\hline Mejit Island & 0.642 & 10.284 & 170.870 & 320 & $1.8464 \times 10^{-24}$ & $7.97697 \times 10^{-28}$ \\
\hline Rongelap & 0.788 & 11.157 & 166.871 & 165 & $3.22866 \times 10^{-18}$ & $5.85974 \times 10^{-22}$ \\
\hline
\end{tabular}


Mission Hazard Assessment for STARS Mission 1 (M1) in the Marshall Islands Area

Table 12: Land Impact Probabilities and Expected Casualties: 3 Second FTS Delay

\begin{tabular}{|c|c|c|c|c|c|c|}
\hline \multirow{2}{*}{ Name } & Land Area & N. Lat & E. Long & \multirow{2}{*}{ Population } & \multirow{2}{*}{$\begin{array}{l}\text { Land Impact } \\
\text { Probability }\end{array}$} & \multirow{2}{*}{$\begin{array}{l}\text { Expected } \\
\text { Casualties }\end{array}$} \\
\hline & sq. nm. & deg. & deg. & & & \\
\hline Ujae & 0.394 & 8.930 & 165.761 & 209 & $3.14854 \times 10^{-27}$ & $1.44763 \times 10^{-30}$ \\
\hline Utirik & 1.283 & 11.226 & 169.852 & 256 & $1.25379 \times 10^{-11}$ & $2.16839 \times 10^{-15}$ \\
\hline Wotho & 0.875 & 10.169 & 166.011 & 89 & $3.50904 \times 10^{-23}$ & $3.09363 \times 10^{-27}$ \\
\hline \multicolumn{7}{|c|}{ Wotje Atoll } \\
\hline Ormed & 0.254 & 9.554 & 170.151 & 210 & $3.61271 \times 10^{-28}$ & $2.58891 \times 10^{-31}$ \\
\hline Wotje & 0.718 & 9.457 & 170.241 & 252 & $1.36471 \times 10^{-29}$ & $4.1516 \times 10^{-33}$ \\
\hline
\end{tabular}



Mission Hazard Assessment for STARS Mission 1 (M1) in the Marshall Islands Area

Table 13: Land Impact Probabilities and Expected Casualties: 4 Second FTS Delay

\begin{tabular}{|c|c|c|c|c|c|c|}
\hline \multirow{2}{*}{ Name } & Land Area & N. Lat & E. Long & \multirow{2}{*}{ Population } & \multirow{2}{*}{$\begin{array}{l}\text { Land Impact } \\
\text { Probability }\end{array}$} & \multirow{2}{*}{$\begin{array}{c}\text { Expected } \\
\text { Casualties }\end{array}$} \\
\hline & sq. nm. & deg. & deg. & & & \\
\hline \multicolumn{7}{|c|}{ Ailinginae Atoll } \\
\hline Majokoryaan & 0.118 & 11.1320 & 166.5270 & 0 & $4.64495 \times 10^{-15}$ & 0 \\
\hline \multicolumn{7}{|l|}{ Bikar Atoll } \\
\hline Bikar & 0.065 & 12.1862 & 170.1033 & 0 & $1.24507 \times 10^{-07}$ & 0 \\
\hline \multicolumn{7}{|l|}{ Bikini Atoll } \\
\hline Bikinı & 0.632 & 11.6277 & $165.54 \div 0$ & 0 & $2.48726 \times 10^{-19}$ & 0 \\
\hline \multicolumn{7}{|l|}{ Ailuk Atoll } \\
\hline Ailuk & 0.204 & 10.217 & 169.982 & 465 & $9.39821 \times 10^{-15}$ & $1.8568 \times 10^{-17}$ \\
\hline Enijabro & 0.145 & 10.4504 & 169.9563 & 3 & $7.13436 \times 10^{-14}$ & $1.2794 \times 10^{-18}$ \\
\hline Kapen & 0.223 & 10.4588 & 169.9500 & 4 & $1.22214 \times 10^{-13}$ & $1.90009 \times 10^{-18}$ \\
\hline \multicolumn{7}{|l|}{ Erikub Atoll } \\
\hline Erikub & 0.136 & 9.0200 & 170.0616 & 0 & $1.15955 \times 10^{-21}$ & 0 \\
\hline \multicolumn{7}{|c|}{ Kwajalein Atoll } \\
\hline Big Bustard & 0.009 & 8.762 & 167.739 & 7 & $1.09904 \times 10^{-20}$ & $7.40914 \times 10^{-24}$ \\
\hline Biggerann & 0.152 & 9.337 & 167.060 & 12 & $1.4435 \times 10^{-15}$ & $9.87765 \times 10^{-20}$ \\
\hline Ebadon & 0.350 & 9.328 & 166.827 & 38 & $1.54692 \times 10^{-15}$ & $1.45573 \times 10^{-19}$ \\
\hline Ebeye & 0.088 & 8.780 & 167.739 & 8500 & $1.45166 \times 10^{-19}$ & $1.21535 \times 10^{-20}$ \\
\hline Ebioaji & 0.023 & 8.836 & 167.740 & 10 & $9.6809 \times 10^{-20}$ & $3.64826 \times 10^{-23}$ \\
\hline Eniwetak & 0.018 & 9.017 & 167.716 & 4 & $1.58222 \times 10^{-18}$ & $3.04755 \times 10^{-22}$ \\
\hline Ennubirr & 0.038 & 9.366 & 167.496 & 380 & $8.24113 \times 10^{-16}$ & $7.14307 \times 10^{-18}$ \\
\hline Ennylabegan & 0.155 & 8.799 & 167.618 & 98 & $4.12272 \times 10^{-19}$ & $2.25931 \times 10^{-22}$ \\
\hline Enubuj & 0.105 & 8.749 & 167.685 & 60 & $1.1132 \times 10^{-19}$ & $5.51358 \times 10^{-23}$ \\
\hline Gagan & 0.009 & 9.288 & 167.538 & 8 & $6.03562 \times 10^{-17}$ & $4.65016 \times 10^{-20}$ \\
\hline Gellinam & 0.009 & 9.099 & 167.729 & 6 & $2.90493 \times 10^{-18}$ & $1.67858 \times 10^{-21}$ \\
\hline Gugeegue & 0.073 & 8.849 & 167.744 & 10 & $3.79718 \times 10^{-19}$ & $4.50854 \times 10^{-23}$ \\
\hline
\end{tabular}


Mission Hazard Assessment for STARS Mission 1 (M1) in the Marshall Islands Area

Table 13: Land Impact Probabilities and Expected Casualties: 4 Second FTS Delay

\begin{tabular}{|c|c|c|c|c|c|c|}
\hline \multirow{2}{*}{ Name } & Land Area & N. Lat & E. Long & \multirow{2}{*}{ Population } & \multirow{2}{*}{$\begin{array}{l}\text { Land Impact } \\
\text { Probability }\end{array}$} & \multirow{2}{*}{$\begin{array}{l}\text { Expected } \\
\text { Casualties }\end{array}$} \\
\hline & sq. nm. & deg. & deg. & & & \\
\hline Kwajalein & 0.948 & 8.723 & 167.737 & 3446 & $6.06719 \times 10^{-19}$ & $1.91158 \times 10^{-21}$ \\
\hline Legan & 0.035 & 8.984 & 167.579 & 6 & $2.08464 \times 10^{-18}$ & $3.0975 \times 10^{-22}$ \\
\hline $\begin{array}{l}\text { Little } \\
\text { Bustard }\end{array}$ & 0.003 & 8.755 & 167.737 & 5 & $3.26939 \times 10^{-21}$ & $4.72295 \times 10^{-24}$ \\
\hline Meck & 0.047 & 9.003 & 167.727 & 255 & $3.23794 \times 10^{-18}$ & $1.52268 \times 10^{-20}$ \\
\hline Omelek & 0.012 & 9.050 & 167.743 & 1 & $1.73415 \times 10^{-18}$ & $1.25257 \times 10^{-22}$ \\
\hline Roi-Namur & 0.510 & 9.396 & 167.476 & 470 & $1.75154 \times 10^{-14}$ & $1.39909 \times 10^{-17}$ \\
\hline \multicolumn{7}{|l|}{ Lae Atoll } \\
\hline Lae & 0.230 & 8.921 & 166.264 & 192 & $4.45395 \times 10^{-19}$ & $3.22267 \times 10^{-22}$ \\
\hline Lib Island & 0.230 & 8.3160 & 167.3800 & 140 & $2.75686 \times 10^{-22}$ & $1.4545 \times 10^{-25}$ \\
\hline \multicolumn{7}{|l|}{ Likiep Atoll } \\
\hline Jibal & 0.156 & 9.888 & 169.276 & 70 & $1.02418 \times 10^{-14}$ & $3.98335 \times 10^{-18}$ \\
\hline Lado & 0.189 & 9.8425 & 169.3105 & 20 & $5.93128 \times 10^{-15}$ & $5.4402 \times 10^{-19}$ \\
\hline Likeip & 0.510 & 9.823 & 169.303 & 406 & $1.31156 \times 10^{-14}$ & $9.04988 \times 10^{-18}$ \\
\hline Mato & 0.461 & 10.044 & 168.997 & 30 & $7.4375 \times 10^{-13}$ & $4.19513 \times 10^{-17}$ \\
\hline Mero & 0.148 & 9.895 & 169.265 & 60 & $1.12102 \times 10^{-14}$ & $3.93913 \times 10^{-18}$ \\
\hline \multicolumn{7}{|c|}{ Maleolap Atoll } \\
\hline Airik & 0.204 & 8.5033 & 171.1980 & 220 & $2.98603 \times 10^{-29}$ & $2.79116 \times 10^{-32}$ \\
\hline Kaven & 0.612 & 8.8983 & 170.8460 & 95 & $2.24421 \times 10^{-24}$ & $3.01948 \times 10^{-28}$ \\
\hline Ollot & 0.102 & 8.7708 & 171.1810 & 80 & $2.17078 \times 10^{-27}$ & $1.47572 \times 10^{-30}$ \\
\hline $\mathrm{Tar}$ & 0.081 & 8.8383 & 171.0967 & 29 & $1.19615 \times 10^{-26}$ & $3.71189 \times 10^{-30}$ \\
\hline Tjan & 0.102 & 8.9075 & 170.8950 & 0 & $2.85303 \times 10^{-25}$ & 0 \\
\hline Mejit Island & 0.642 & 10.284 & 170.870 & 320 & $2.55216 \times 10^{-16}$ & $1.10261 \times 10^{-19}$ \\
\hline Rongelap & 0.788 & 11.157 & 166.871 & 165 & $3.40495 \times 10^{-13}$ & $6.17968 \times 10^{-17}$ \\
\hline Ujae & 0.394 & 8.930 & 165.761 & 209 & $7.59224 \times 10^{-20}$ & $3.49075 \times 10^{-23}$ \\
\hline
\end{tabular}



Mission Hazard Assessment for STARS Mission 1 (M1) in the Marshall Islands Area

Table 13: Land Impact Probabilities and Expected Casualties: 4 Second FTS Delay

\begin{tabular}{|c|c|c|c|c|c|c|}
\hline \multirow{2}{*}{ Name } & Land Area & N. Lat & E. Long & \multirow{2}{*}{ Population } & \multirow{2}{*}{$\begin{array}{l}\text { Land Impact } \\
\text { Probability }\end{array}$} & \multirow{2}{*}{$\begin{array}{l}\text { Expected } \\
\text { Casualties }\end{array}$} \\
\hline & sq. $\mathrm{nm}$. & deg. & deg. & & & \\
\hline Utirik & 1.283 & 11.226 & 169.852 & 256 & $1.19955 \times 10^{-09}$ & $2.07457 \times 10^{-13}$ \\
\hline Wotho & 0.875 & 10.169 & 166.011 & 89 & $2.89305 \times 10^{-15}$ & $2.55057 \times 10^{-19}$ \\
\hline \multicolumn{7}{|c|}{ Wotje Atoll } \\
\hline Ormed & 0.254 & 9.554 & 170.151 & 210 & $1.84487 \times 10^{-18}$ & $1.32205 \times 10^{-21}$ \\
\hline Wotje & 0.718 & 9.457 & 170.241 & 252 & $8.46544 \times 10^{-19}$ & $2.57527 \times 10^{-22}$ \\
\hline
\end{tabular}


Mission Hazard Assessment for STARS Mission 1 (M1) in the Marshall Islands Area

Table 14: Probabilities of Impacts Within Keepout Zones

\begin{tabular}{|c|c|c|c|c|c|}
\hline \multirow{2}{*}{$\begin{array}{c}\text { Names of } \\
\text { Reference Areas }\end{array}$} & \multirow{2}{*}{$\begin{array}{c}\text { Keep-out } \\
\begin{array}{c}\text { Circle } \\
\text { radius }\end{array} \\
n \mathrm{~nm} .\end{array}$} & \multirow{2}{*}{$\begin{array}{c}\begin{array}{c}\text { Center } \\
\text { Longitude }\end{array} \\
\text { deg. }\end{array}$} & \multirow{2}{*}{$\begin{array}{c}\begin{array}{c}\text { Center } \\
\text { Latitude }\end{array} \\
\text { deg. }\end{array}$} & \multicolumn{2}{|c|}{ Expected Number of Impacts } \\
\hline & & & & $\begin{array}{l}\text { FTS Delay } \\
3 \text { Seconds }\end{array}$ & $\begin{array}{l}\text { FTS Delay } \\
4 \text { Seconds }\end{array}$ \\
\hline Ailinglapalap Atoll & 24.00 & 168.700 & 7.380 & 0. & $0.362131 \times 10^{-24}$ \\
\hline Ailuk Atoll & 21.00 & 169.950 & 10.330 & $0.199252 \times 10^{-12}$ & $0.719298 \times 10^{-09}$ \\
\hline Aron Atoll & 21.00 & 171.660 & 7.150 & 0. & $0.118654 \times 10^{-37}$ \\
\hline Aur Atoll & 16.80 & 171.169 & 8.220 & 0. & $0.891691 \times 10^{-26}$ \\
\hline Bikini Atoll & 27.00 & 165.400 & 11.600 & $0.404341 \times 10^{-29}$ & $0.175950 \times 10^{-14}$ \\
\hline Ebon Atoll & 15.00 & 168.690 & 4.610 & 0. & 0. \\
\hline Enewetak Atoll & 24.00 & 162.384 & 11.425 & 0. & $0.712605 \times 10^{-33}$ \\
\hline Jabwot Island & 12.60 & 168.980 & 7.756 & 0. & $0.433553 \times 10^{-23}$ \\
\hline Jaluit Atoll & 21.60 & 169.600 & 6.000 & 0. & $0.707375 \times 10^{-41}$ \\
\hline Kili Island & 13.20 & 169.118 & 5.646 & 0. & 0. \\
\hline $\begin{array}{l}\text { Kwajalein Atoll NE } \\
\text { (Roi Namuir, Gagan, } \\
\text { Ennubirr) }\end{array}$ & 15.60 & 167.500 & 9.300 & $0.237118 \times 10^{-11}$ & $0.218998 \times 10^{-10}$ \\
\hline $\begin{array}{l}\text { Kwajalein Atoll East } \\
\text { Middle } \\
\text { (Eniwetak, Gellinam, } \\
\text { Meck, Omelek) }\end{array}$ & 15.00 & 167.730 & 9.050 & $0.172174 \times 10^{-15}$ & $0.367121 \times 10^{-12}$ \\
\hline $\begin{array}{l}\text { Kwajalein Atoll SE } \\
\text { (Kwajalein, etc) }\end{array}$ & 16.20 & 167.680 & 8.800 & $0.290050 \times 10^{-19}$ & $0.989938 \times 10^{-14}$ \\
\hline $\begin{array}{l}\text { Kwajalein Atoll } \\
\text { South Middle (Legan) }\end{array}$ & 12.60 & 167.579 & 8.984 & $0.139245 \times 10^{-16}$ & $0.782281 \times 10^{-13}$ \\
\hline $\begin{array}{l}\text { Kwajalein Atoll NW } \\
\text { (Ebadon) }\end{array}$ & 12.00 & 166.827 & 9.328 & $0.288655 \times 10^{-06}$ & $0.288655 \times 10^{-06}$ \\
\hline $\begin{array}{l}\text { Kwajalein Atoll NW } \\
\text { (Biggerann) }\end{array}$ & 12.60 & 167.060 & 9.337 & $0.288059 \times 10^{-11}$ & $0.113963 \times 10^{-10}$ \\
\hline Lae Atoll & 12.60 & 166.262 & 8.921 & $0.386452 \times 10^{-19}$ & $0.220065 \times 10^{-14}$ \\
\hline
\end{tabular}


Mission Hazard Assessment for STARS Mission 1 (M1) in the Marshall Islands Area

Table 14: Proba:yilities of Impacts Within Keepout Zones

\begin{tabular}{|l|c|c|c|c|c|}
\hline \multirow{2}{*}{$\begin{array}{c}\text { Names of } \\
\text { Reference Areas }\end{array}$} & $\begin{array}{c}\text { Keep-out } \\
\text { Circle } \\
\text { radius }\end{array}$ & $\begin{array}{c}\text { Center } \\
\text { Longitude }\end{array}$ & $\begin{array}{c}\text { Center } \\
\text { Latitude }\end{array}$ & \multicolumn{2}{|c|}{ Expected Number of Impacts } \\
\cline { 2 - 6 } & nm. & deg. & deg. & $\begin{array}{c}\text { FTS Delay } \\
3 \text { Seconds }\end{array}$ & $\begin{array}{c}\text { FTS Delay } \\
4 \text { Seconds }\end{array}$ \\
\hline \hline Lib Island & 12.60 & 167.378 & 8.313 & $0.344117 \times 10^{-29}$ & $0.147348 \times 10^{-17}$ \\
\hline Likiep Atoll & 22.80 & 169.100 & 9.900 & $0.675902 \times 10^{-11}$ & $0.154106 \times 10^{-08}$ \\
\hline Majuro Atoll & 21.60 & 171.250 & 7.100 & 0. & $0.596141 \times 10^{-36}$ \\
\hline Maloelap Atoll & 24.00 & 171.000 & 8.750 & $0.153736 \times 10^{-38}$ & $0.382 .122 \times 10^{20}$ \\
\hline Megit Island & 12.60 & 170.870 & 10.284 & $0.170353 \times 10^{-19}$ & $0.375849 \times 10^{-12}$ \\
\hline Mili Atoll & 22.80 & 171.825 & 6.125 & 0. & 0. \\
\hline Namorik Atoll & 13.20 & 168.127 & 5.613 & 0. & $0.168156 \times 10^{-42}$ \\
\hline Namu Atoll & 22.80 & 168.140 & 8.000 & $0.715125 \times 10^{-36}$ & $0.725901 \times 10^{-19}$ \\
\hline Rongelap Atoll & 0.60 & 166.871 & 11.357 & $0.622345 \times 10^{-18}$ & $0.225715 \times 10^{-12}$ \\
\hline Ujae Atoll & 24.00 & 165.650 & 9.050 & $0.943908 \times 10^{-2.1}$ & $0.411400 \times 10^{-14}$ \\
\hline Ujelang Atoll & 21.60 & 160.949 & 9.776 & $n$ & $0.951664 \times 10^{-40}$ \\
\hline Utirik Atoll & 18.00 & 169.800 & 11.276 & $0.191749 \times 10^{-06}$ & $0.956075 \times 10^{-05}$ \\
\hline Wotho Atoll & 18.00 & 166.011 & 16.119 & $0.512677 \times 10^{-17}$ & $0.561369 \times 10^{-11}$ \\
\hline Wotje Atoll & 27.00 & 170.000 & 9.400 & $0.598931 \times 10^{-21}$ & $0.735401 \times 10^{-13}$ \\
\hline
\end{tabular}




\section{Conclusions}

The expected casualty value ( $E_{c}$, the likelihood that the STARS M1 flight will cause a casualty) in the Marshall Islands area is no greater than $2.08 \times 10^{-13}$, which compares favorably to the generally accepted ${ }^{1}$ value of $10^{-6}$. The probability of a debris fragment impacting an inhabited land area is less than $1.20 \times 10^{-9}$. The probability of a debris fragment impacting within the keep-out zones (as defined in Table 14) is less than $1.92 \times 10^{-7}$ or $9.56 \times 10^{-6}$ for 3 or 4 second flight termination system delays, respectively.

Presentations of these results to the ranges has been received favorably. Moreover, an analysis done by Tybrin Corp. under contract by KMR has apparently resulted in similar numbers (although Sandia has not received a copy of their final report.) Hence, it is anticipated that the ranges will not deny range safety approval for STARS M1 based on the downrange portion of the flight (which is the subject of this report).

1. Keese, David L., and Barton. William R.. Risk Assessment and Its Application to Flight Safety Analysis, SAND89-1982. 


\section{Appendix A. Raw Impact Data Plots}

Appendix A contains plots which show the results of the investigation of the tumble turn failure modes. The plots show the fragment impact distributions for the hard-over nozzle, stuck nozzle, and return to null position failure modes as well as the results of investigation of the instantaneous destruct failure mode.

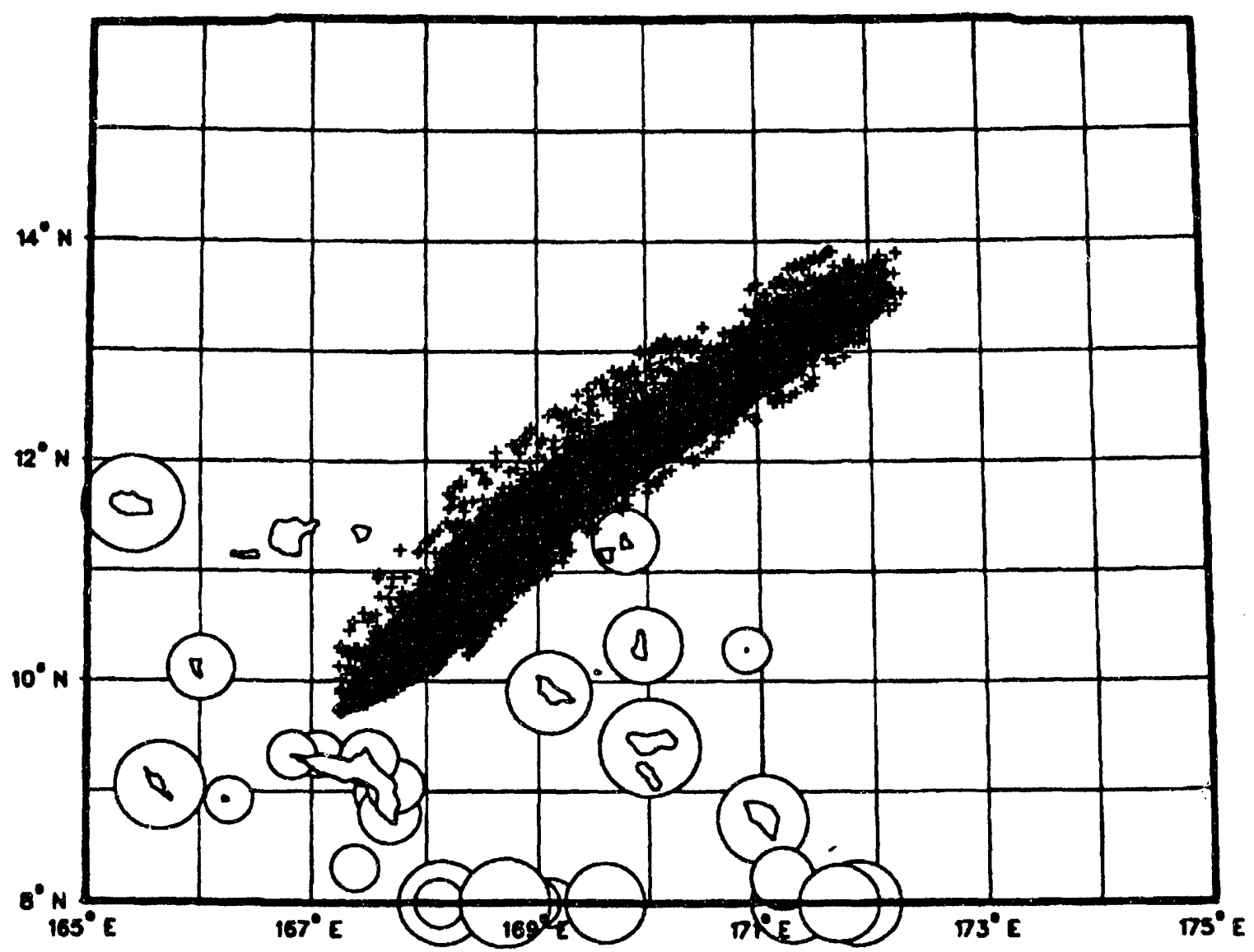

Figure 11: Hard Over Nozzle Tumble Turn Failure Mode

With Initial State Covariance Matrix and With 3 Second Delay 


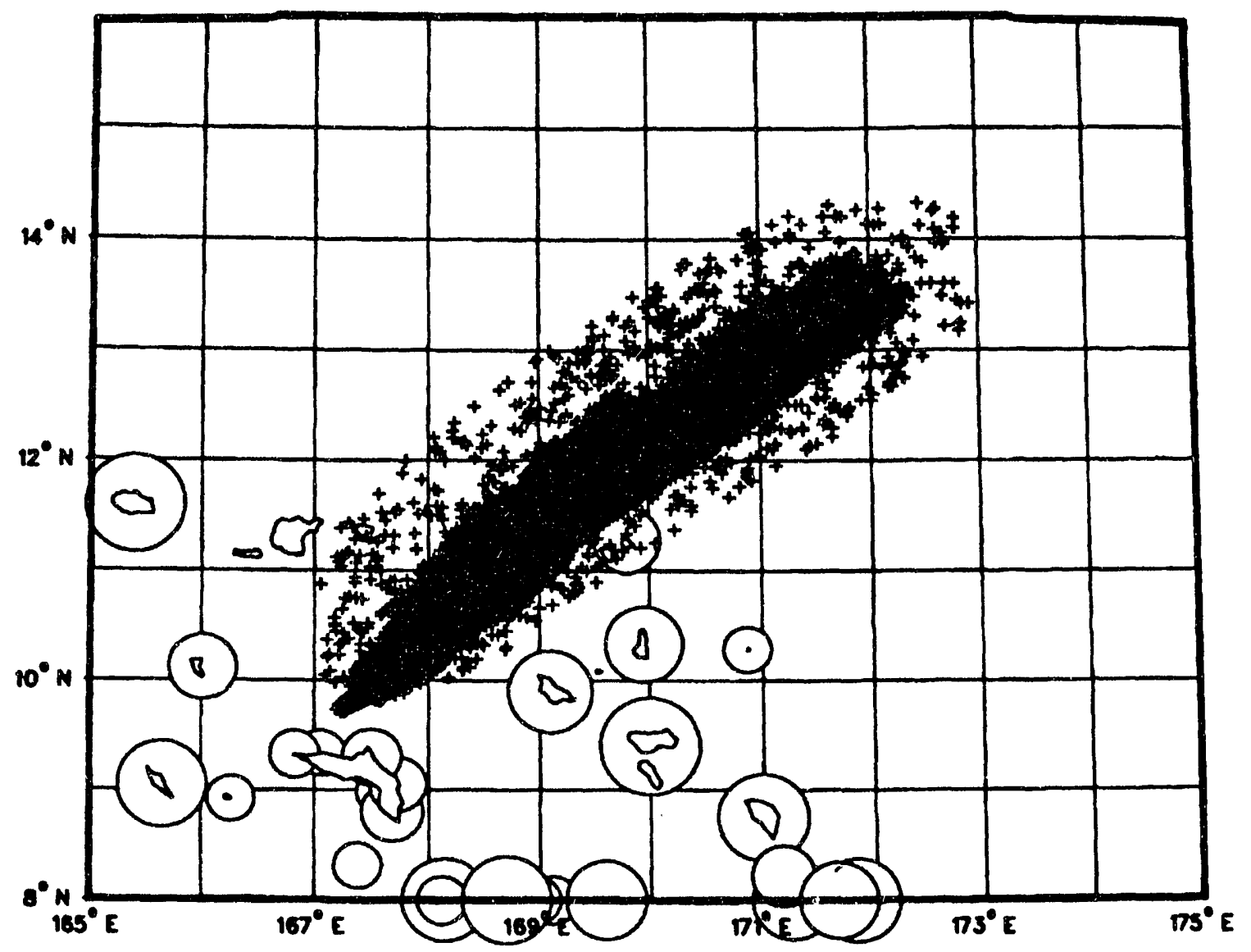

Figure 12: Hard Over Nozzle Tumble Turn Failure Mode With Initial State Covariance Matrix and With 4 Second Delay 


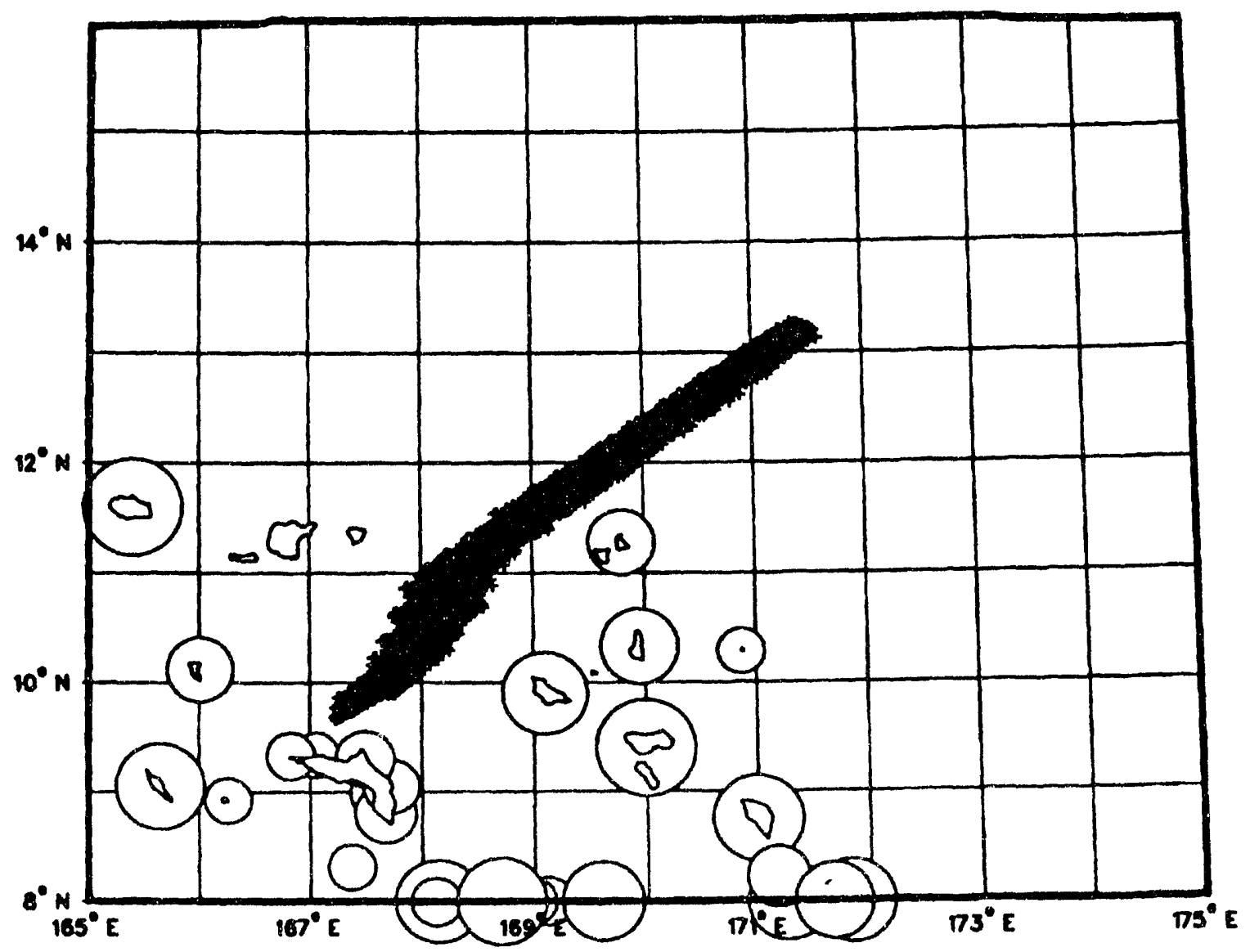

Figure 13: Stuck Nozzle Tumble Turn Failure Mude With Initial State Covariance Matrix and With 3 Second Delay 


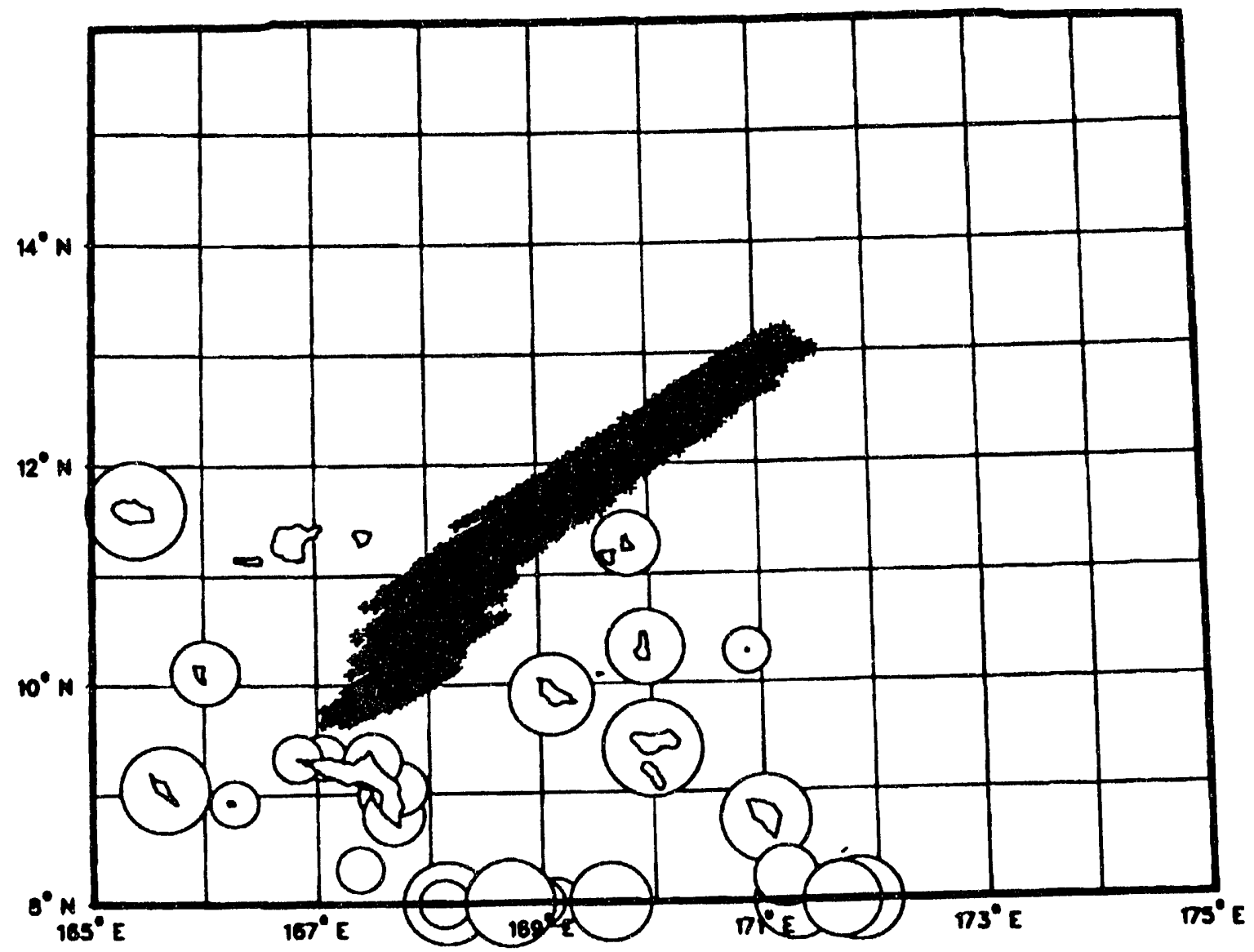

Figure 14: Stuck Nozzle Tumble Turn Failure Mode With Initial State Covariance Matrix and With 4 Second Delay 


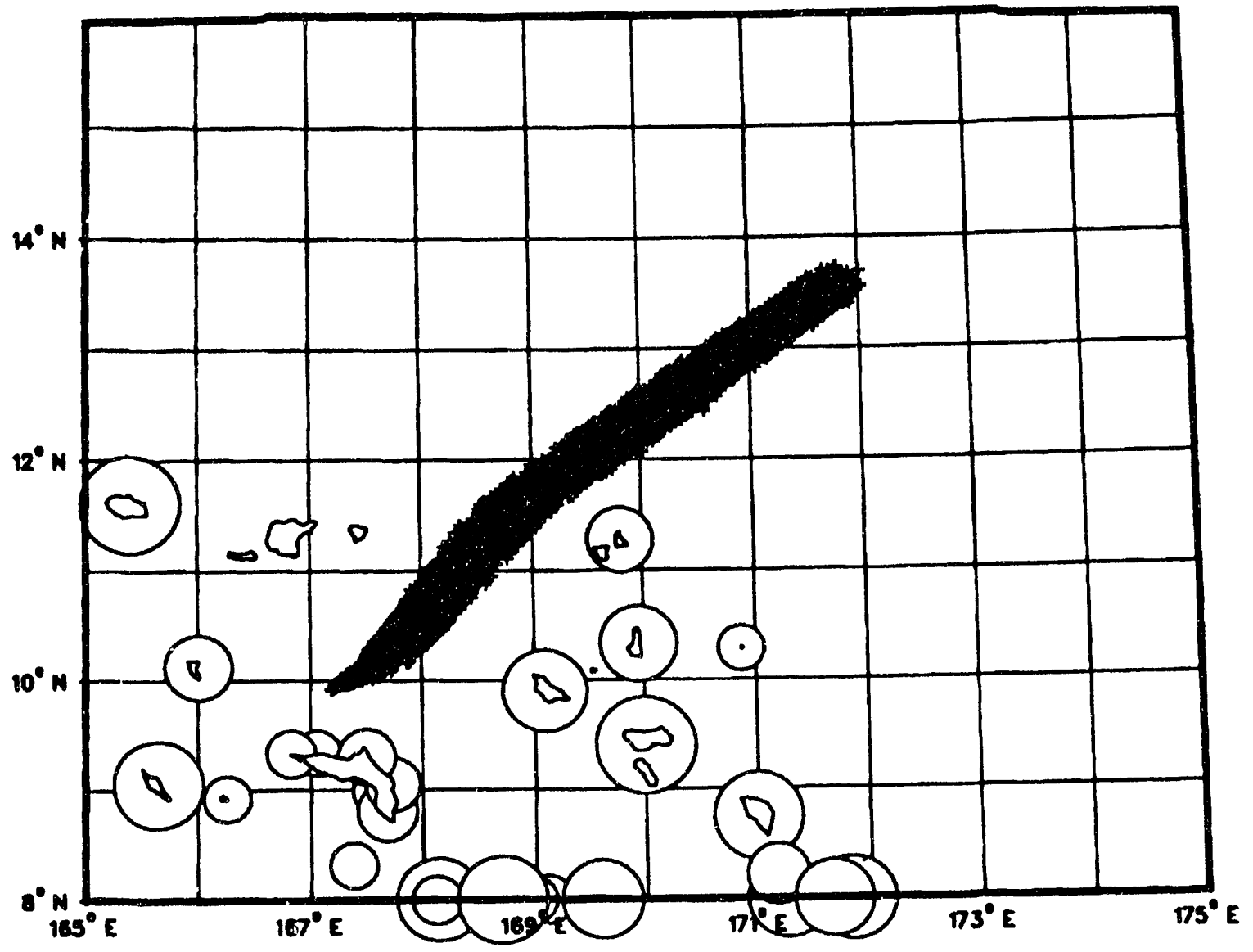

Figure 15: Null Position Nozzle Tumble Turn Failure Mode With Initial State Covariance Matrix and With 3 Second Delay 


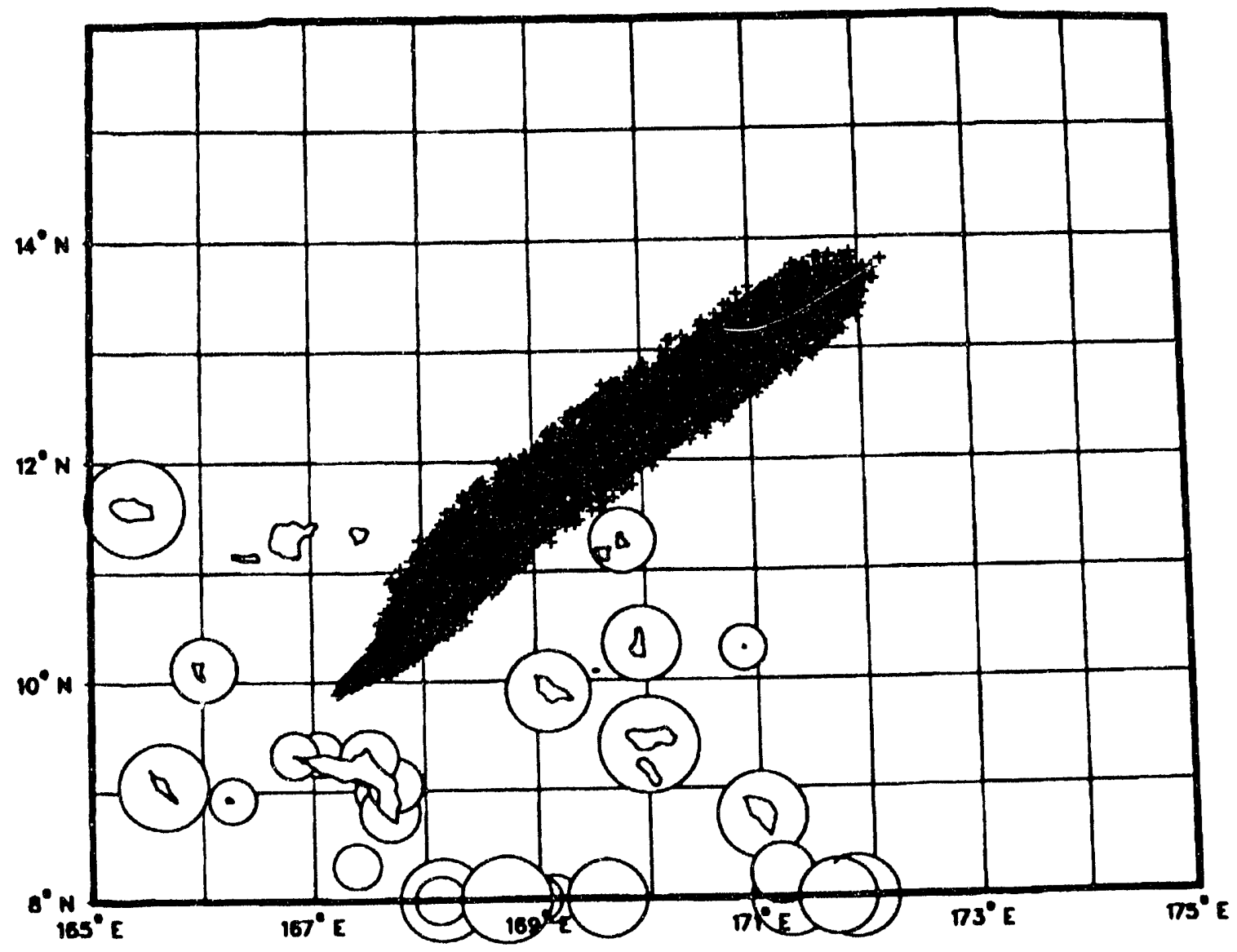

Figure 16: Null Position Nozzle Tumble Turn Failure Mode With Initial State Covariance Matrix and With 4 Second Delay 


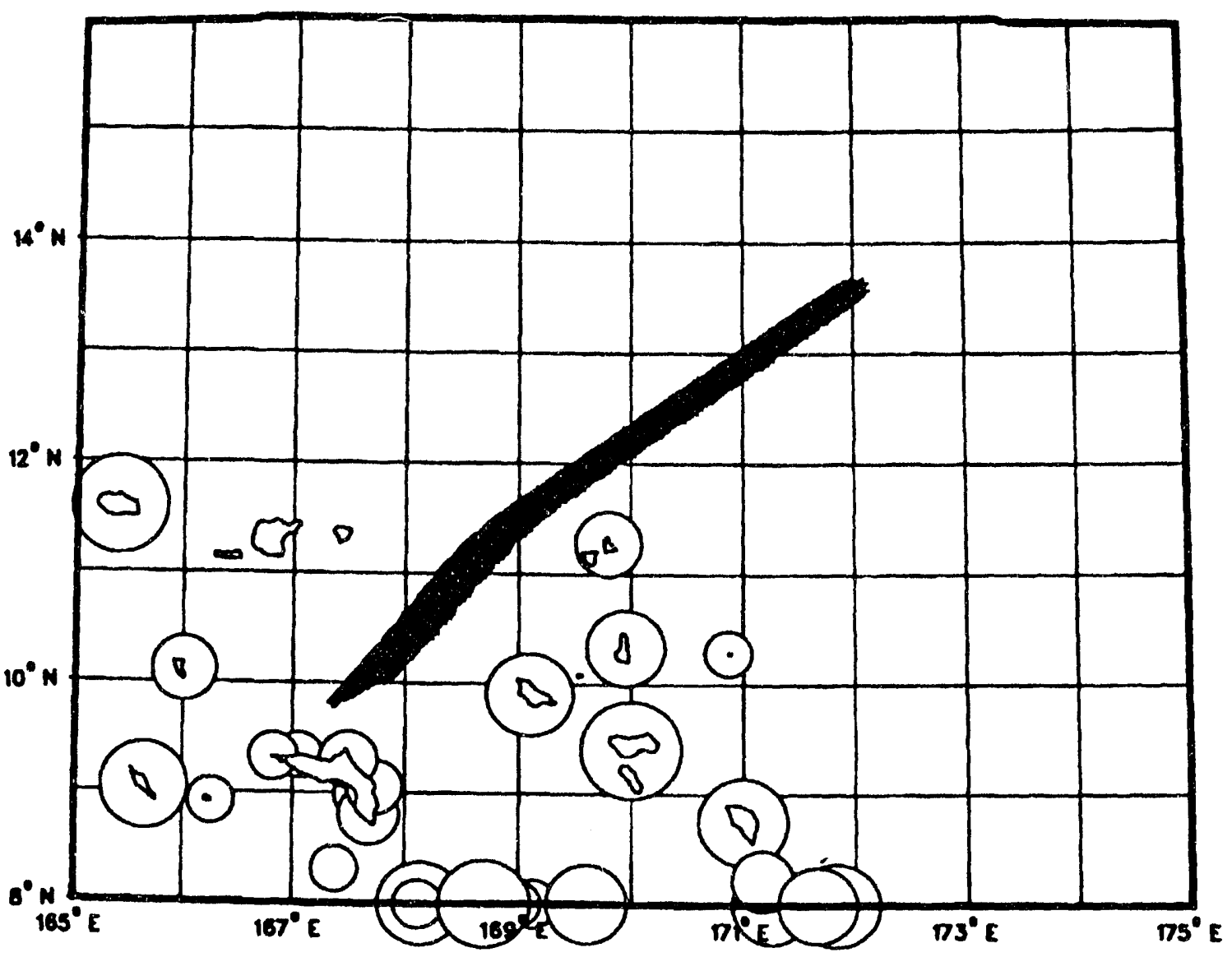

Figure 17: Instantaneous Destruct Failure Mode With Initial State Covariance Matrix 


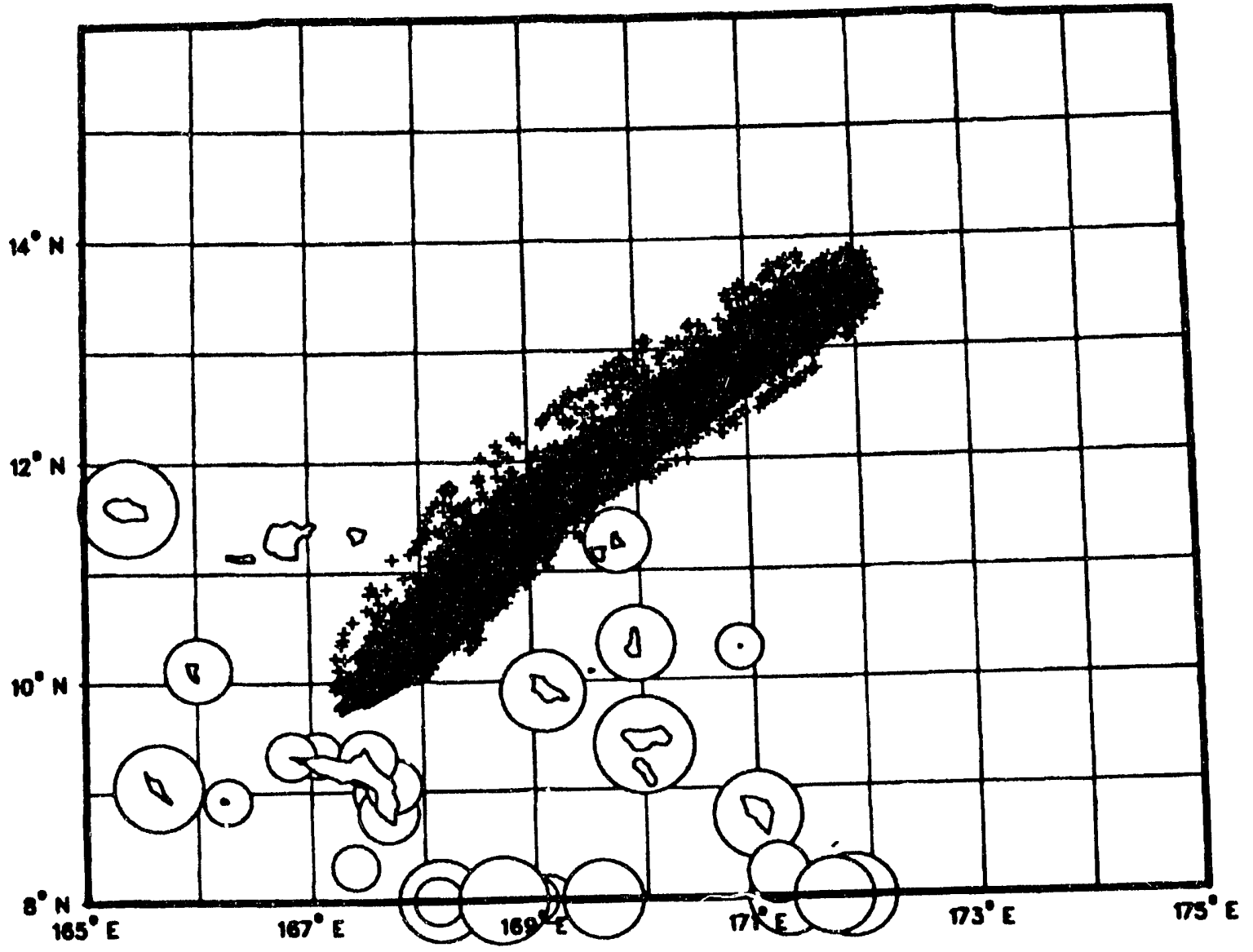

Figure 18: Hard Over Nozzle Tumble Turn Failure Mode With 3 Second Delay Between Failure on Nominal Trajectory and FTS Activation 


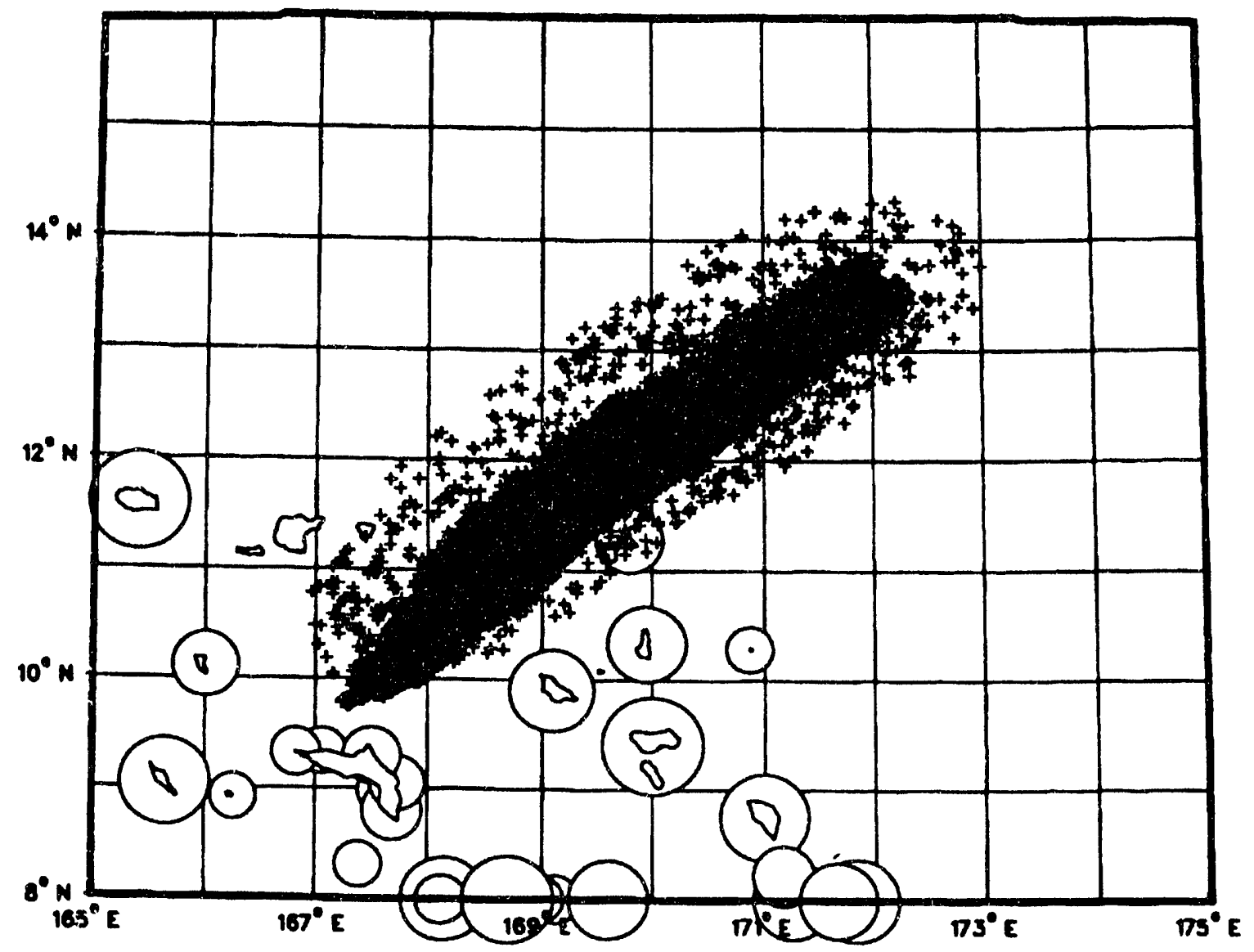

Figure 19: Hard Over Nozzle Tumble Turn Failure Mode With 4 Second Delay Between Failure on Nominal Trajectory and FTS Activation 


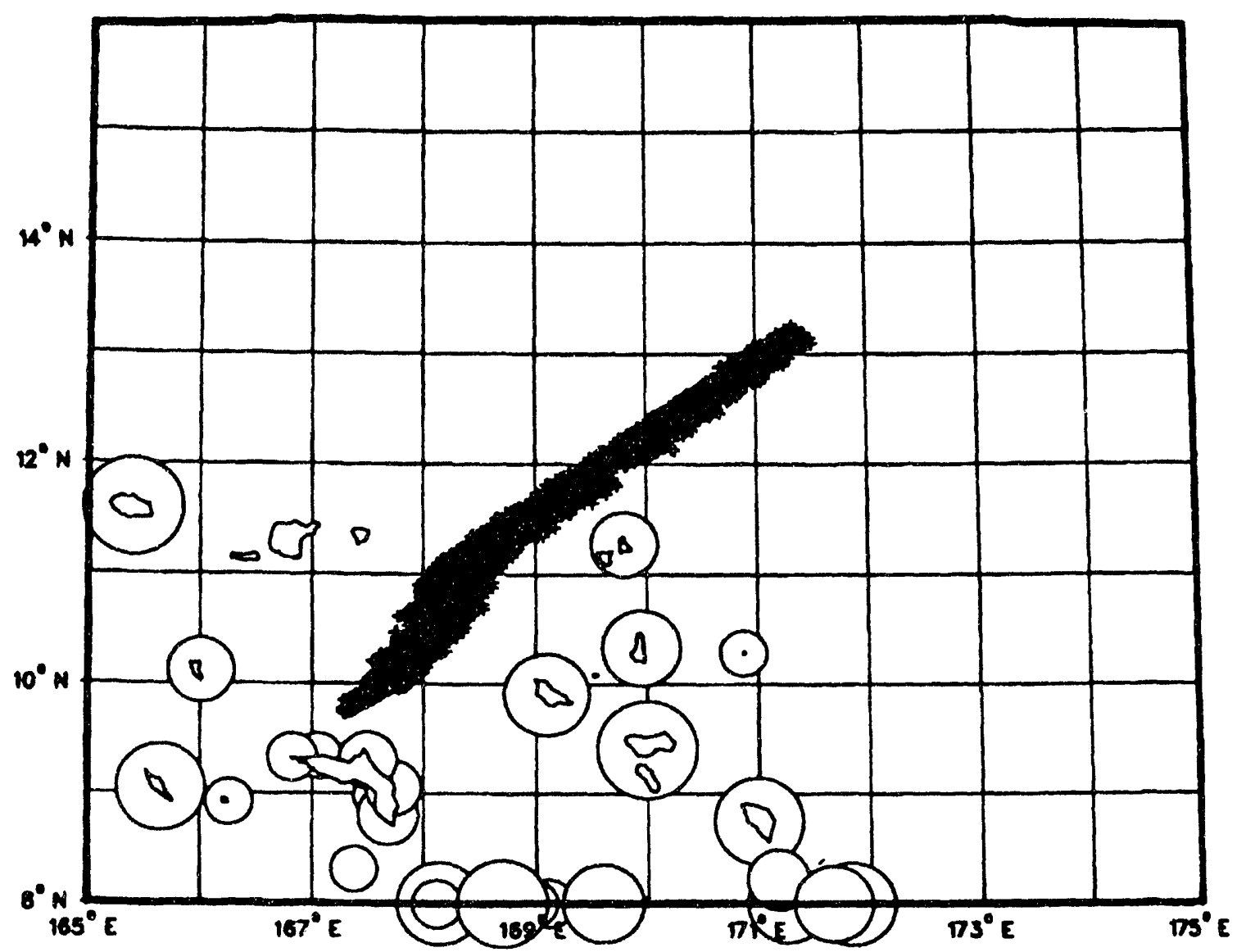

Figure 20: Stuck Nozzle Tumble Turn Failure Mode With 3 Second Delay Between Failure on

Nominal Trajectory and FTS Activation 


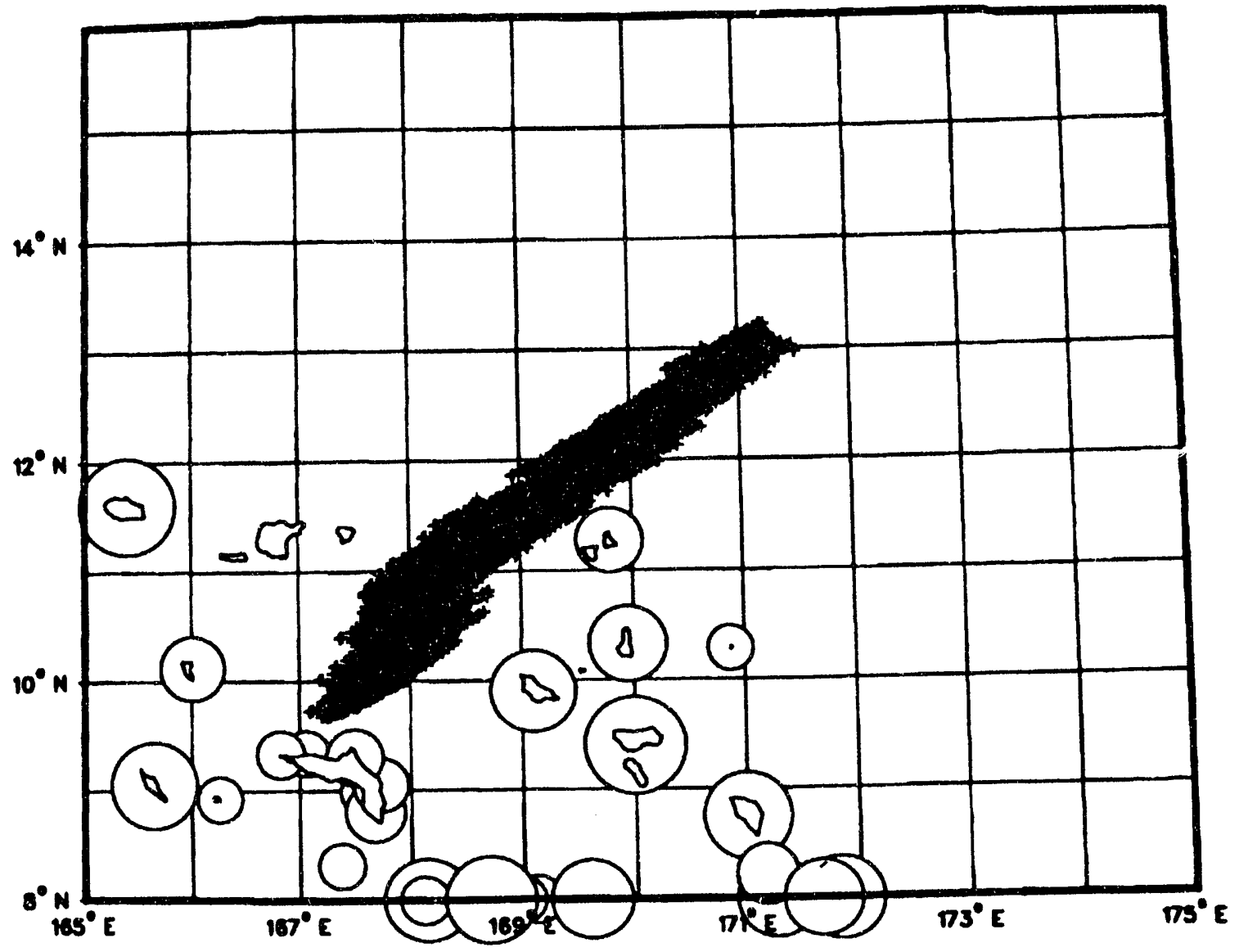

Figure 21: Stuck Nozzle Tumble Turn Failure Mode With 4 Second Delay Between Failure on Nominal Trajectory and FTS Activation 


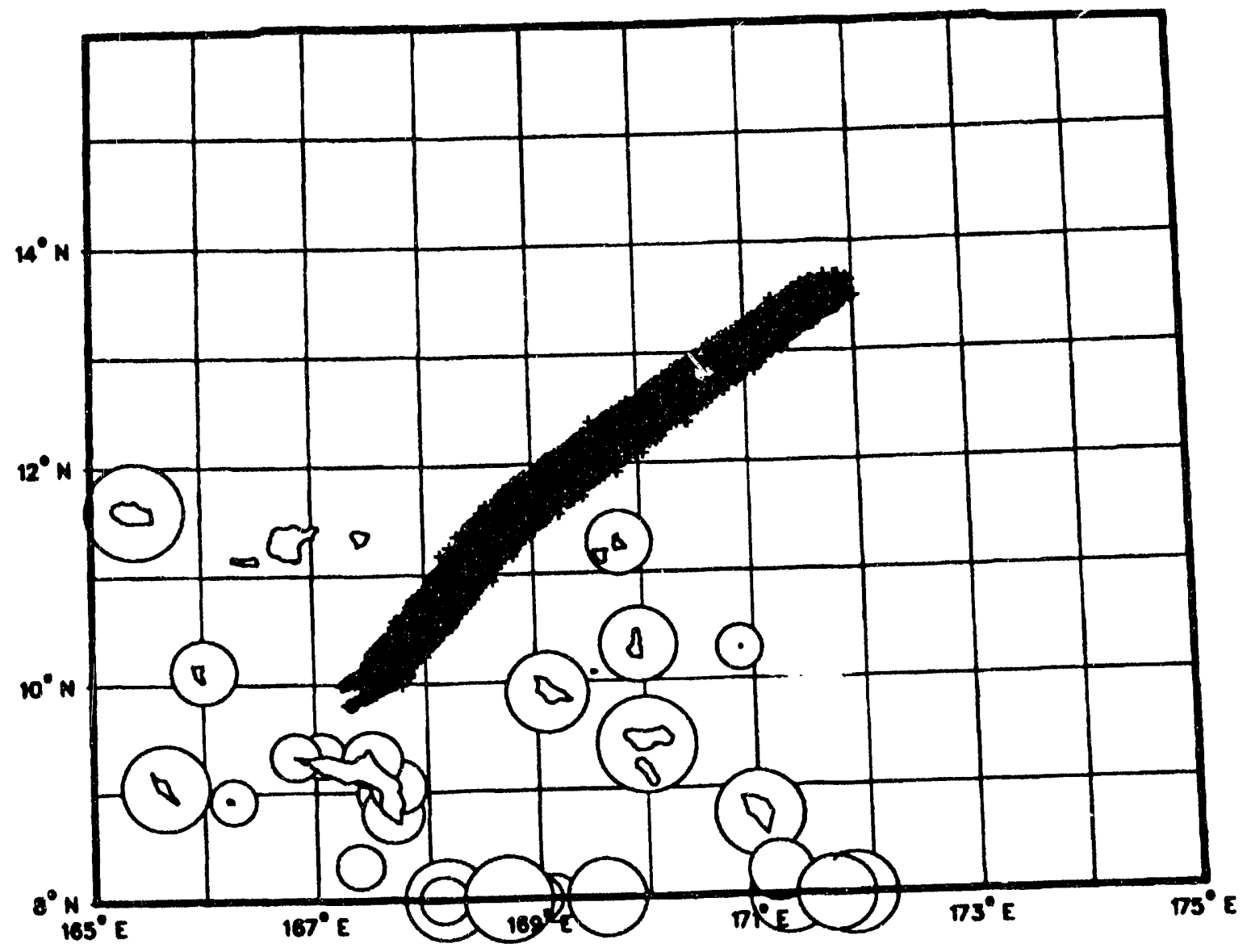

Figure 22: Null Position Nozzle Tumble Turn Failure Mode With 3 Second Delay Between Failure on Nominal Trajectory and FTS Activation 


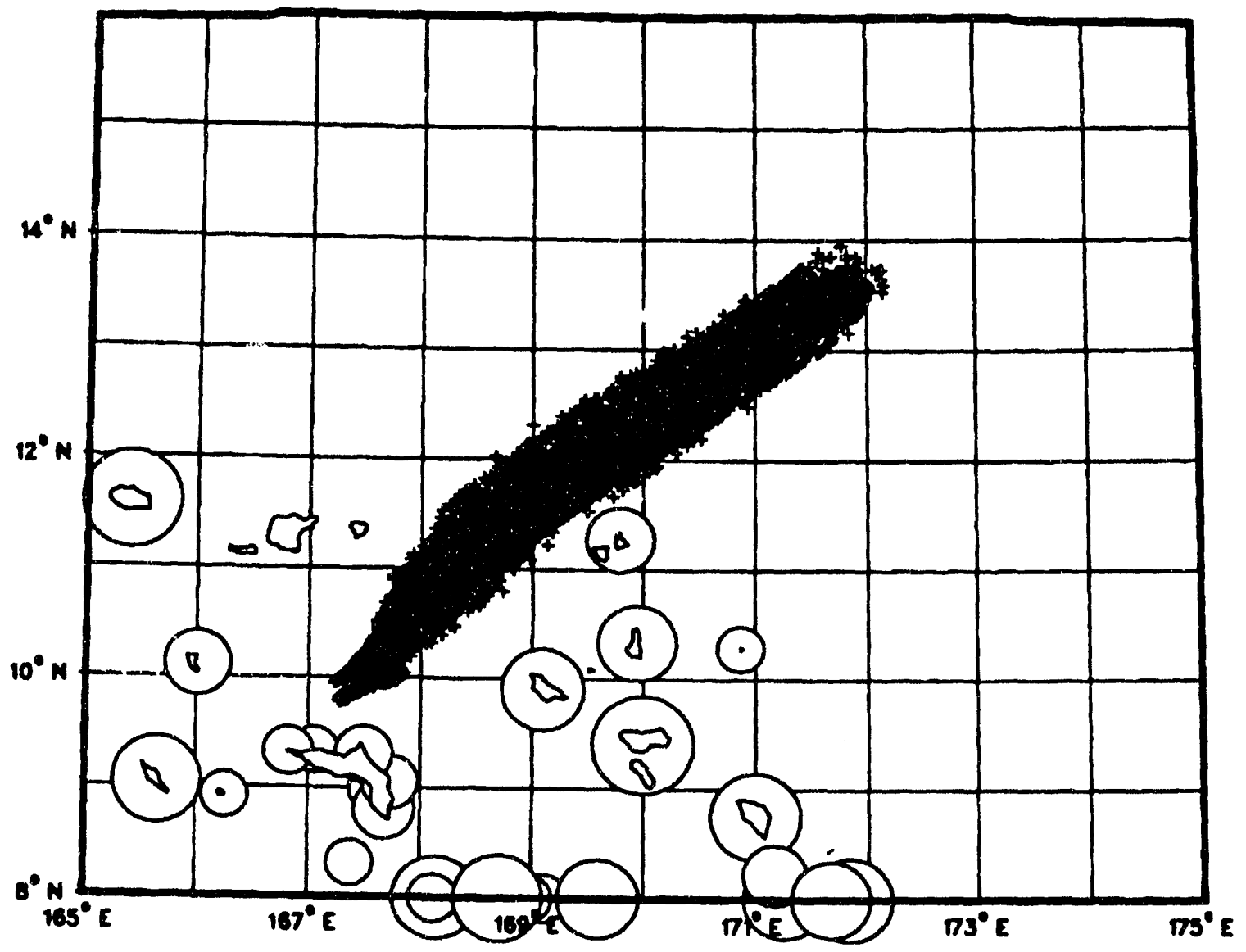

Figure 23: Null Position Nozzle Tumble Turn Failure Mode With 4 Second Delay Between Failure on Nominal Trajectory and FTS Activation 


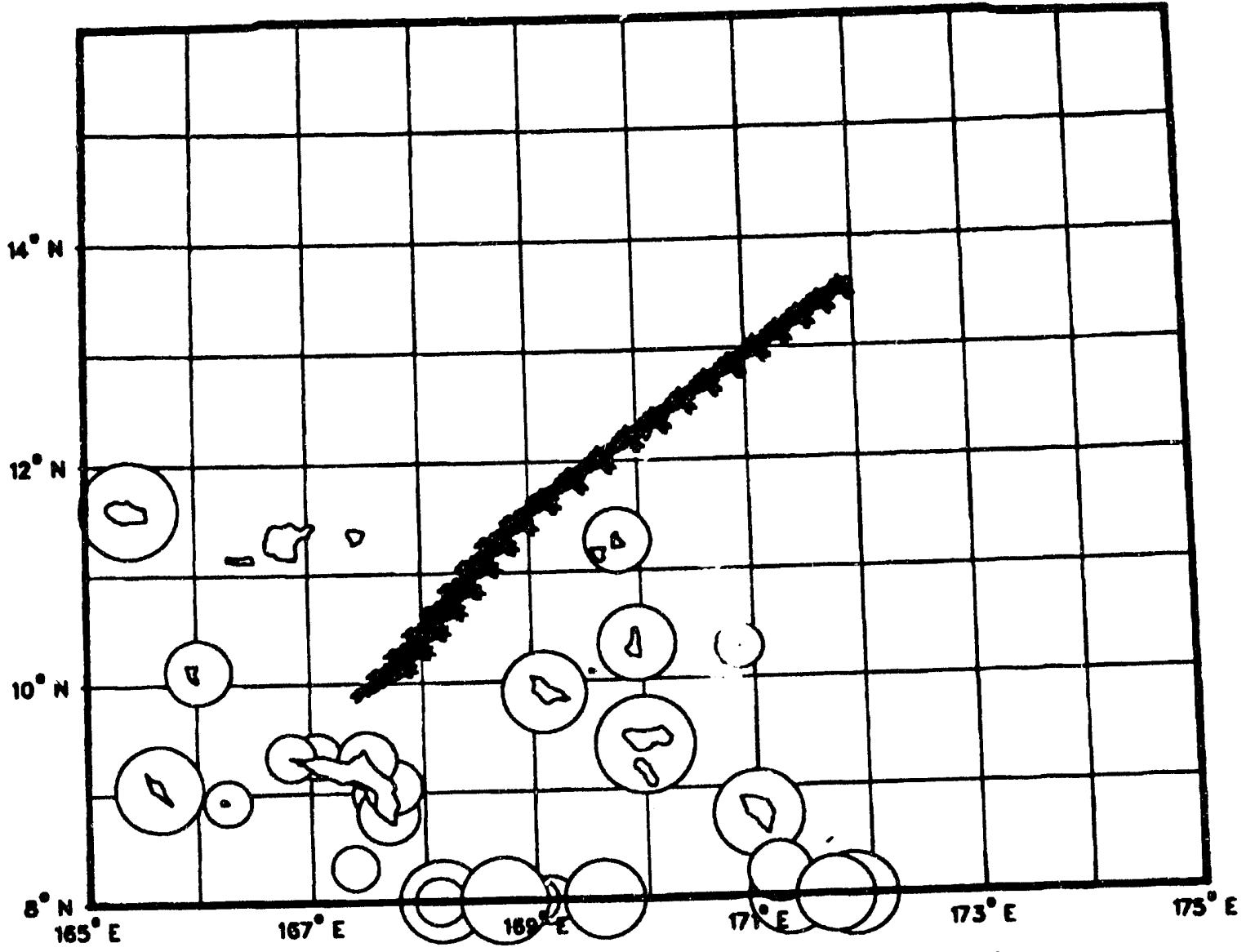

Figure 24: Instantaneous Destruct Failure Mode on Nominal Trajectory 
Mission Hazard Assessment for STARS Mission 1 (M1) in the Marshall Islands Area

\section{Distribution}

\section{External Distribution}

1. Jack McCreary

USA SSDC

STARS Product Office

P. O. Box 1500

Huntsville, AL 35807 - 3801

2. Irene Hofer

NAWC WPNS

Safety Office, Code P3411

Pt. Mugu, CA 93042

3. Aubrey Kunishige

Pacific Missile Range Facility

Code 7332F

Barking Sands, HI 96752 - 0128

4. Robert Valencia

KMR Safety Office

USAKA CSSD - KA - RS

P. O. Box 26

APO San Francisco, CA 96555 - 2526

5. Russell George

Tybrin Corporation

4900 University Square, Suite 28

Huntsville, AL 35807
Internal Distributiona

6. 1500 David J. McCloskey

7. 1501

8. 1502

Carl W. Peterson

route to: $1512,1513,1552$

Paul J. Hommert

route to: $1511,1553,1554$

9. 1551 Walter P. Wolfe

10. 1551 Kenneth V. Chavez

11. 1551 J. Kenneth Cole

12. 1551 Teresa M. Jordan

13. 1551 Marc W. Kniskern

14. 1551 Robert A. LaFarge

15. 1551 William A. Millard

16. 1551 David E. Outka (5)

17. 1551 Larry W. Young

18. 1561 Harold S. Morgan

route to: 1562

19. 2723 Richard G. Hay

20. 2723 Alonzo A. Lopez

21. 2725 Eric J. Schindwolf

22. 2725 Margaret R. Weber

23. 7141 Technical Library (5)

24. 7151 Technical Publications

25. 7613-2 Document Processing for DOE/OSTI (10)

26. 8523 Central Technical Files

27. 9101 Alfred C. Watts

28. 9132 Rance S. Edmunds

29. 9132 John E. White 

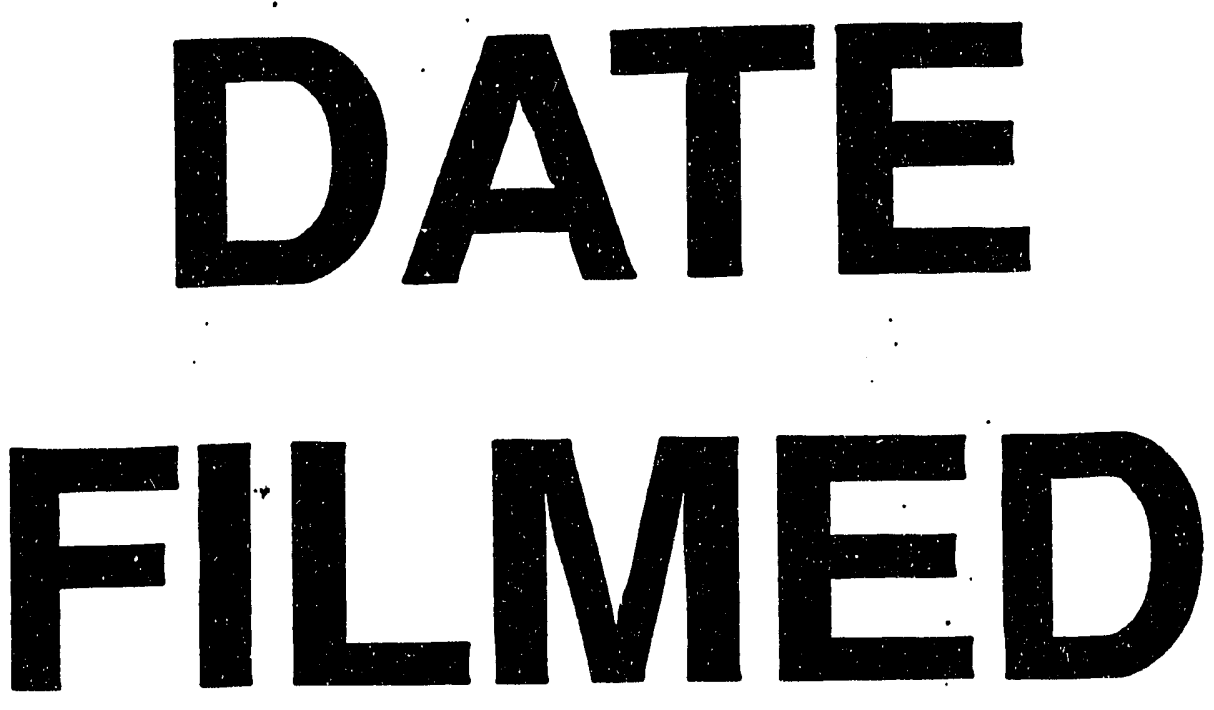

$12 / 14 / 93$
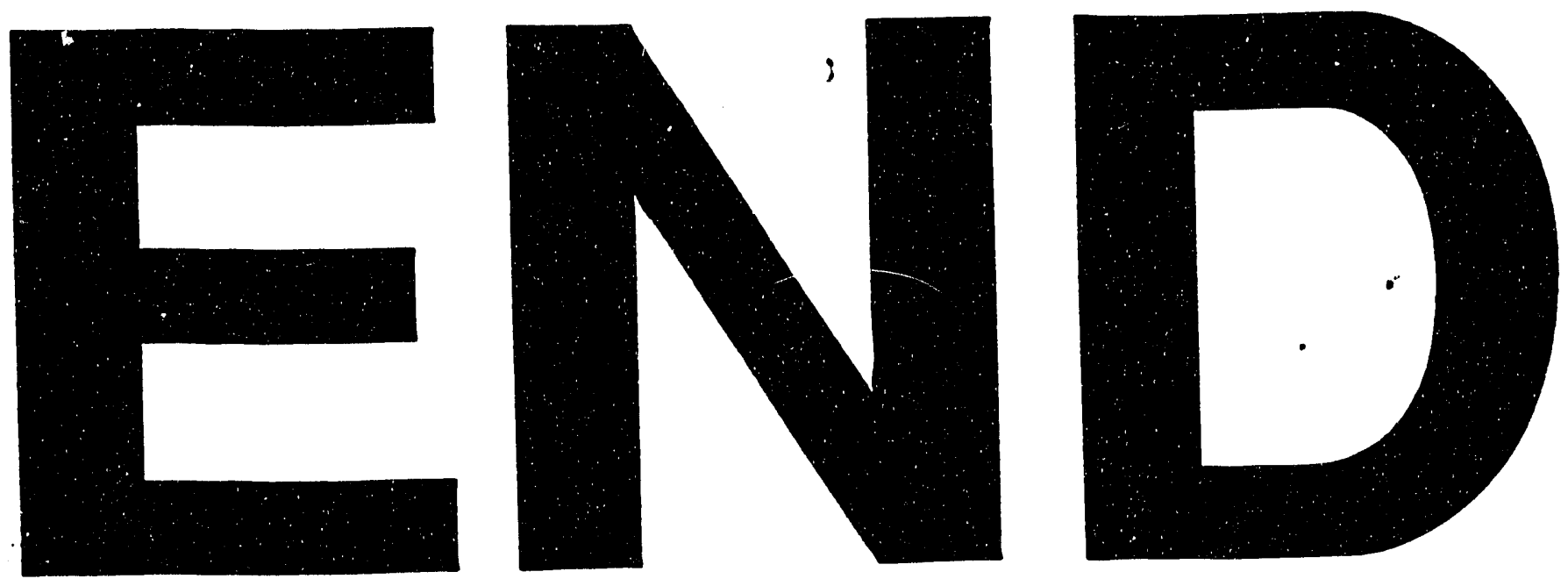
